University of Windsor

Scholarship at UWindsor

7-17-1966

\title{
Self-licking deprivation and maternal behaviour in the primiparous
}

rat.

Theodore Horvath

University of Windsor

Follow this and additional works at: https://scholar.uwindsor.ca/etd

\section{Recommended Citation}

Horvath, Theodore, "Self-licking deprivation and maternal behaviour in the primiparous rat." (1966). Electronic Theses and Dissertations. 6427.

https://scholar.uwindsor.ca/etd/6427

This online database contains the full-text of PhD dissertations and Masters' theses of University of Windsor students from 1954 forward. These documents are made available for personal study and research purposes only, in accordance with the Canadian Copyright Act and the Creative Commons license-CC BY-NC-ND (Attribution, Non-Commercial, No Derivative Works). Under this license, works must always be attributed to the copyright holder (original author), cannot be used for any commercial purposes, and may not be altered. Any other use would require the permission of the copyright holder. Students may inquire about withdrawing their dissertation and/or thesis from this database. For additional inquiries, please contact the repository administrator via email (scholarship@uwindsor.ca) or by telephone at 519-253-3000ext. 3208. 


\section{INFORMATION TO USERS}

This manuscript has been reproduced from the microfilm master. UMI films the text directly from the original or copy submitted. Thus, some thesis and dissertation copies are in typewriter face, while others may be from any type of computer printer.

The quality of this reproduction is dependent upon the quality of the copy submitted. Broken or indistinct print, colored or poor quality illustrations and photographs, print bleedthrough, substandard margins, and improper alignment can adversely affect reproduction.

In the unlikely event that the author did not send UMI a complete manuscript and there are missing pages, these will be noted. Also, if unauthorized copyright material had to be removed, a note will indicate the deletion.

Oversize materials (e.g., maps, drawings, charts) are reproduced by sectioning the original, beginning at the upper left-hand corner ard continuing from left to right in equal sections with small overlaps.

ProQuest Information and Learning 300 North Zeeb Road, Ann Arbor, MI 48106-1346 USA 800-521-0600

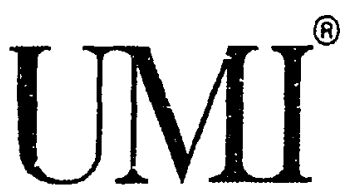




\section{SELF-LICKING DEPRIVATION AND MATERNAI \\ BEHAVIOUR IN THE PRIMIPAROUS RAT}

by

THEODORE HORVATH, B.A.

Waterloo University College, 1965

\section{A Thesis}

Submitted to the Faculty of Graduate studies through the Department of Psychology in Partial Fulfillment of the Requirements for the Degree of Master of Arts at the

University of

windsor

$$
\begin{gathered}
\text { Windsor, Ontario, Canada } \\
1966
\end{gathered}
$$


UMI Number: EC52608

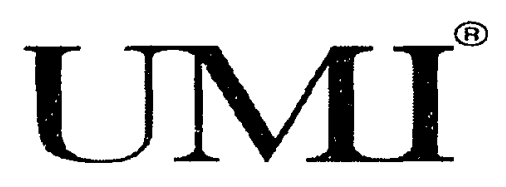

UMI Microform EC52608

Copyright 2007 by ProQuest Information and Learning Company.

All rights reserved. This microform edition is protected against unauthorized copying under Title 17, United States Code.

ProQuest Information and Learning Company

789 East Eisenhower Parkway

P.O. Box 1346

Ann Arbor, MI 48106-1346 


\section{APPROVED BI:}

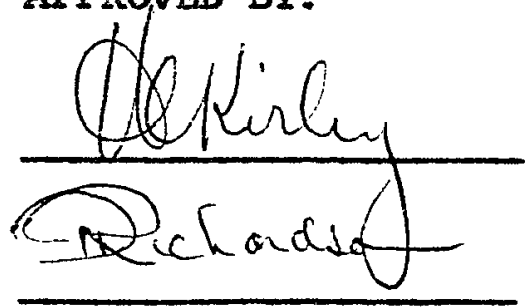

$1+62$

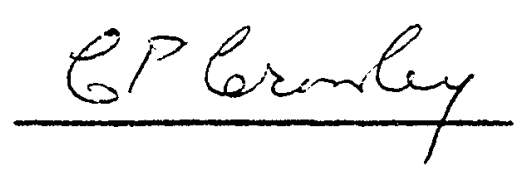




\section{ABSTRACT}

The purpose of this experiment was to rear female rats under various degrees of self-licking deprivation to test the hypothesis that good maternal behaviour is dependent upon prior self-licking experiences.

Self-licking was prevented by the placement of rubber collars about the necks of the subjects. The subjects, reared individually, were collared at weaning age (2l days) and decollared shortly before parturition of their litters. The design of the collars was such that four collared experimental groups were permitted varying degrees of selflicking and collar-licking from weaning age to full maturity. A control group was reared under identical conditions except that these subjects were not collared.

Measures were implemented which assessed the effectiveness of the collaring treatments in preventing selflicking and collar-licking. Other measures, designed to assess the adequacy of maternal behaviour, were performed. The analyses of the data measures showed that maternal behaviour is independent of the amount of prior selflicking experience. The status of collar-licking as a basis upon which maternal behaviour may be mediated remains to be determined. 


\section{PREFACE}

The nature-nurture controversy is very much a live issue in modern psychology. My interest in this fascinating area of research was first aroused when, as an undergraduate, I had occasion to read Bindra's provocative text on motivation.

I should like to express my deep appreciation to Dr. H.W. Kirby under whose direction this study was undertaken. His guidance and energetic participation contributed largely to the successful execution of the experiment. Thanks are also due to Rev. C.P. Crowley and to Mr. D. Richardson who served capably as readers. Finally, I extend profound thanks to my wife, Barbara, who endured endless hours at a typewriter in the preparation of the thesis manuscripts, and whose encouragement sustained me through a long and difficult task.

\section{iii}


TABLE OF CONTENTS

\begin{tabular}{|c|c|c|}
\hline & & Page \\
\hline PREFACE & & iii \\
\hline LIST OF & TABLES & $v i$ \\
\hline IIST OF & FIGURES & viii \\
\hline Chapter & & \\
\hline $\mathbf{I}$ & INTRODUCTION & 1 \\
\hline & Background of Problem Area & 1 \\
\hline & The Present Problem & 5 \\
\hline II & PREIIMINARY OBSERVATIONS & 12 \\
\hline & Maternal Behaviour & 12 \\
\hline & Grooming & 15 \\
\hline III & METHODOLOGY & 19 \\
\hline & General Procedures & 19 \\
\hline & Measures & 27 \\
\hline IV & OBSERVATIONS AND RESULTS & 34 \\
\hline & Part I: supplementary Observations & 34 \\
\hline & Part II: Results & 41 \\
\hline $\mathrm{V}$ & DISCUSSION & 58 \\
\hline & Interpretation of Results & 58 \\
\hline & Experimental considerations & 63 \\
\hline $\mathrm{VI}$ & SUMMARY AND CONCLUSIONS & 71 \\
\hline SUGGESTIC & ONS FOR FURTHER RESEARCH & 74 \\
\hline APPENDIX & A Conical collar specifications & 75 \\
\hline APPENDIX & Figure 1 & 77 \\
\hline APPENDIX & Vaginal Smear Technique & 78 \\
\hline APPENDIX & Observation Box Specifications & 79 \\
\hline
\end{tabular}


APPENDIX E Reasons for Subject Rejection 80

APPENDIX F Figures 2 and 3

APPENDIX G Figures 4 and 5

$\begin{array}{lll}A P P E N D I X & H & \text { Figures } 6 \text { and } 7\end{array}$

$\begin{array}{lll}\text { APPENDIX I } & \text { Figure } 8 & 84\end{array}$

APPENDIX J Subject Weight Data 85

APPENDIX K Subject Weight Data 86

APPENDIX I Subject Weight Data 87

APPENDIX M Abdominal-Genital Cleanliness Data 88

APPENDIX N Eighty-Fifth Day Licking Behaviour Data 89

APPENDIX O Contact Latency Data 90

APPENDIX P Contact Latency Data 91

APPENDIX Q Percentage Retrieved Data 92

APPENDIX R Percentage Retrieved Data 93

$\begin{array}{lll}\text { APPENDIX S Pup Survival Data } & 94\end{array}$

BIBLIOGRAPHY $\quad 95$

$\begin{array}{ll}\text { VITA AUCTORIS } & 97\end{array}$ 


\section{LIST OF TABLES}

Table

2 Analysis of Variance of Parental Population Weights at Twenty-one Days of Age

3 Analysis of Variance of Parental Population weights on the First Day of Pregnancy

4 Multiple comparisons of Mean Weights of Treatment Groups on the First Day of Pregnancy by the Duncan New Multiple Range Test

5 Analysis of Variance of Parental Population Weights on the TwentyFixst Day of Pregnancy

6 Analysis of Variance of AbdominalGenital cleanliness Scores

7 Multiple comparisons of AbdominalGenital cleanliness scores of the Treatment Groups by the Duncan New Multiple Range Test

8 Analysis of Variance of Eighty-Fifth Day Licking Behaviour Scores

9 Analysis of Variance of contact Latency scores on the First-Day Retrieving Test

10 Analysis of Variance of contact Latency Scores on the Fifth-Day Retrieving Test 
11 Multiple comparisons of the contact Latency Scores of the Treatment Groups on the Fifth-Day Retrieving Test by the Duncan New Multiple Range Test

12 Analysis of Variance of Percentage of Pups Retrieved on the First-Day Retrieving Test

13 Analysis of Variance of Percentage of Pups Retrieved on the Fifth-Day Retrieving Test

14 Number of Pups Per Mother to Survive to Twenty-One Days of Age by Parental Treatment Groups

15 Analysis of Variance of Pup Survival Percentage

16 Analyses and Results of Subsidiary Measures 


\section{LIST OF FIGURES}

Figure

1 Self-licking by a notched collar

Page subject

2 Body-1icking by a notched collar subject

3 Crouch position adopted by an unnotched collar subject during

"Phantom" face-washing

4 "Phantom" forepaw-licking by an unnotched collar subject

5 "Phantom" collar-brushing by an unnotched collar subject

6 "Phantom" body-licking by an unnotched collar subject

$7 \quad$ Notched collar subject licking

hind claw

8 "Phantom" hind-claw-licking by an unnotched collar subject 
CHAPTER I

\section{INTRODUCTION}

\section{Background of Problem Area}

A specific behaviour, i.e., what an organism does, or is engaged in doing, at a given moment, can have one of two origins. It may be innately determined or environmentally determined.

There are four types of behaviour which can be labelled innately determined. First, there are behaviours which are a natural consequence of the organism's genetically determined anatomical construction. For example, the hunting technique of the Cheetah, the physique of which makes it a grand sprinter but a poor climber, differs from that of the Leopard, which is equipped to be an excellent climber but a poor sprinter. Second, there are behaviours that directly result from the normal development and maturation of physiological processes. The crowing of roosters, for example, is a direct function of the production of gonadal hormones that accompany sexual maturity. Third, there are instances in which environmental factors stim- 
ulate internal physiological processes, which in turn set off the behaviour. In the migration of birds, for example, decreasing amounts of daylight illumination (days become shorter as fall approaches) cause gonadal changes which affect other bodily processes such that biras seek a warmer climate. Undoubtedly, other factors come into play regarding exact destinations and routes taken, the above being a description only of the stimulus to movement.

The fourth type of innately determined behaviour is so-called "instinctive" behaviour. Many authors use the phrases "innate behaviour" and "instinctive behaviour" interchangeably. The phrase instinctive behaviour properly refers to behaviour patterns which have not been demonstrated to originate in any of the above three manners. To call a behaviour "instinctive" is to express ignorance of the conditions under which it is developed and elicited. Examples of such behaviours in the laboratory rat are grooming, copulatory behaviour, and maternal behaviour. The environmental determination of behaviour can occur in two (or more) ways. The first is learning, in which category is included conditioning. Learning may be generally defined as the development of response habits as a function of continued experience with the circumstan- 
ces. In the laboratory, many of the higher forms of life have shown a considerable capacity to acquire new behaviours by learning. It is reasonable to assume that many of their activities in their natural surroundings are learned. Birds, for example, must learn to fly. It is a process that proceeds by stages and is dependent upon trial and error. The second way in which environmental factors influence behaviour is illustrated by the following example. The migration route taken by hawks and other soaring birds is dependent upon the contour of the terrain and the prevailing winds. These birds require updrafts and, consequently, their routes will be the windward side of mountain chains. This type of behaviour determination is quite capricious and completely a matter of environmental circumstances. One further example is the food intake of animals. Seasonal variation in the availability of foods largely determines what an animal will be feeding on at a given time.

Historically, the dispute as to whether a given behaviour, or behaviour in general, is innately determined or environmentally determined has been called the naturenurture, or heredity-environment, or more recently the instinct-learning controversy. Over the years both points 
of view have had protagonists and antagonists. Extremists on the one side have maintained that all behaviour is genetically determined. The environmentalists, on the other hand, have held to the position that all behaviour depends upon experiential factors. The publication of Darwin's theory of evolution added urgency to the debate. Since the survival of organisms, and consequently of species, depended in part upon behavioural factors, the origin of behaviours became a vital topic. (For a thorough treatment of the nature-nurture controversy see Beach, 1955). Few modern thinkers would adopt an either-or position. Today, behaviour is thought of as an interaction of physiologically determined capacities and tendencies which are actualized by environmental stimuli and learning. This attitude provides for various approaches to the assessment of the relative influence of innate and environmental factors. For instance, geneticists seek to influence hereditary make-up by selective breeding or various methods of mutation induction. Ethologists and zoogeographers study animals in their natural surroundings to determine how committed they are to specific environments. Other investigators use the technique (either surgical intervention or injection) of altering the normal bodily lev- 
el of this or that hormone to assess its influence on behaviour. The animal psychologist's approach is to manipulate the stimulus conditions that normally accompany the behaviour pattern in the attempt to discover the behaviour's relation to the stimuli.

The future will undoubtedly see the rapproachment of these avenues of investigation. The benefits to be derived from such a pooling of resources have recently been realized by authors such as Ratner and Denny (1964).

The Present Problem

Birch (1956) has suggested that rat maternal behaviour may not be as independent of learning as had previously been thought. He raised a group of female rats with wide rubber collars placed about their necks. The collars were of a size such that, while they permitted the animal to walk and move about more or less normally, they prevented any contact between the animal's mouth and the rest of its body. A control group was raised with collars of the same proportions and weights but notched so as to permit body licking. These animals, reared individually, were collared from infancy through adulthood and mating, and were only decollared shortly before par- 
turition of their litters. Birch's technique effectively inhibited the self-licking behaviour of his experimental subjects (Ss) while his controls were permitted this activity. He found that his control ss were excellent mothers, bringing 95 per cent of their pups to weaning age (normally 21 days). His experimental Ss, on the other hand, were very poor mothers, tending to cannibalize and poorly suckle their young, none of which survived to weaning age.

In interpreting his results Birch theorized that the frequent licking of the body in the adult rat represents an established social relationship between the rat (i.e., its head) and parts of its body. of primary importance in this context is the relationship between the rat and its anogenital area. Since the female eats the placental membrane off the pups immediately as they are delivered, Birch contends that the necessary learning for this behaviour develops out of the head-vaginal relationship. Specifically, two things are learned; first, the olfactory and gustatory stimuli emitted by its own body which help the rat relate to its pups (presumably the pups smell and taste much as did the vaginal secretions which, for the few days prior to parturition, preceeded them), and sec- 
ond, in association with these olfactory and gustatory stimuli, the rat learns how to clean her vagina without biting or otherwise injuring this sensitive tissue. This latter learning is held to be essential if the female is to successfully clean but not injure her pups. Birch claims that when his experimental animals were denied exposure to these olfactory and gustatory stimuli they could not learn either to relate to these stimuli or to clean without hurting delicate tissues. As a consequence, their pups had no meaning for them and were cannibalized outright, abandoned, or mothered so inefficiently that none survived (Birch, 1956, p. 283).

Christophersen and Wagman (1965) replicated Birch's experiment and obtained quite different results. As in the Birch study their rat subjects (11 experimental and 10 control) were collared in infancy (11 days) and decollared shortly before delivery of their litters. The experimental group collars used by Christophersen and Wagman were identical in shape to those used by Birch. The control collars used differed from Birch's in that, while they were of the same weight as the experimental collars, they permitted body licking by way of having smaller outside diameters. Christophersen and Wagman report no consistent 
differences in the mothering behavioux of the experimental versus control ss. The survival rate, until weaning, was 73 per cent for the experimental and 75 per cent for the control pups.

Aa a possible explanation for the failure of Christophersen and Wagman's results to compare to those of Birch, the following suggestion is offered. It is a common phenomenon that objects continually in contact with the surface of the body (clothes, rings, watches, etc.) are experienced as "part of the body". The sense receptors adapt to the presence of the object and are stimulated only when the object itself is moved or altered. Neither Birch nor Christophersen and Wagman report on the behaviour of their ss towards their collars as regards chewing, licking, or otherwise manipulating them. However, it might be argued that, if the experimental rats did lick their collars (and thus stimulated their neclss), they may have established a relationship with themselves of the type envisaged by Birch. Collaring an animal would, in effect, create for it an additional bodily appendage to which it might relate, just as it would to any other since the receptors in the neck could provide the necessary secondary sensory feedback. It might be further ar- 
gued that the mere establishment of such a relationship with any part of the body is sufficient to allow the rat to relate to itself and subsequently to its pups. Finally, since the animal would certainly feel a difference in neck and mouth stimulation between those occasions when it was biting and when it was licking the collar, the possibility also exists that the subjects may have learned the different "feel" of these two acts. Thus, the opportunity for the females to acquire both of the learnings, hypothesized by Birch as essential to adequate mothering behaviour, was inherent in the experimental procedure employed in both the Birch and the Christophersen and Wagman studies.

Although the opportunity may have existed in both researches, a further argument must be added to account for the different results of the two studies. A tentative explanation might be that in Birch's experiment the collar material used was distasteful to the Ss while in Christophersen and Wagman's experiment the collar material used had neutral or positive gustatory properties. Thus, in Birch's experiment the animals may have ignored (in a manipulative sense) their collars while in the Christophersen and Wagman study they may have actually 
licked and otherwise manipulated their collars. If collarlicking can serve as an effective substitute for self-licking, such a set of events could account for the different results.

There are some data, reported by Christophersen and Wagman, to support this suggestion. They state that in a pilot study four rats were fitted with experimental type collars and another four with control type collars. Both groups were collared at 100 days of age. After a 20 day "habituation" period licking behaviour observations were initiated and continued in daily 15 minute observation periods over four days. It was reported that the median number of licking responses for control collar ss was 77 (range 7-303). The experimental collar ss did not make any licking contacts with their bodies; they did, however, lick their collars, but no frequency count was taken of this behaviour (Christophersen and wagman, 1965, p. 143). On this basis, it might be argued that the learnings hypothesized by Birch, if they are essential to adequate maternal behaviour, must have taken place in the christophersen and Wagman but not in the Birch experiment. In the present study an attempt will be made to improve upon the procedures of Birch and Christophersen and wag- 
man, and thereby put Birch's "relationship to the self" theory to test, and to establish whether or not collarlicking can serve as an effective substitute for self-licking as the basis of maternal behaviour. The hypothesis in the present experiment, then, is that the maternal behaviour of female rats reared under conditions that prevent licking (either of body or collar) will on the whole be less adequate than that of female rats reared under conditions that permit licking (either of body or collar). 


\section{CHAPTER II \\ PRELIMINARY OBSERVATIONS}

This chapter is devoted to the presentation of information that is prerequisite to the understanding of the present research both as regards the procedures to be used and the measures to be taken. It will consist of a description of rat maternal behaviour and rat grooming behaviour.

\section{Maternal Behaviour}

There are four groups of response patterns which are subsumed under the term maternal behaviour, all of which are assumed to be "instinctive" in the normally reared rat. These are: nest building, behaviour at parturition, nursing, and retrieving.

Nest Building

It is usually observed that a day or two before parturition, but especially after the delivery of the Iitter of pups, the female rat will gather any suitable material that is available to her and fashion a nest. Its 
construction generally begins from a crudely shaped pile of gathered material in which she first makes a central depression and then proceeds to build up the edges in a saucer-shaped form. The nest is most often located in the darkest and most protected area (of cage or ground) available. In the laboratory, the position of the nest can easily be determined by controlling the surrounding illumination such that a shadow is cast over the desired location. The nest normally deteriorates ten to twenty days after parturition.

Behaviour at Parturition

The female may assist in the delivery of the pups by bending down and literally pulling the fetus out of the vaginal tract as soon as enough of it has emerged as can be grasped with the incisor teeth. Alternatively, the pups may be delivered by muscular contractions of the lower abdomen alone. In either case, immediately as the pup is delivered, the female attends it and begins to lick it. She first cleans off the placental membrane; she then eats the placenta itself, chewing it up slowly until she reaches the belly of the pup, at which point she neatly nips off the umbilical cord. After having done this she con- 
tinues to lick and clean the pup, rolling it over gently with her forepaws. The delivery of each pup is typically at about six minute intervals, which allows enough time for the cleaning of one pup before the delivery of the next. The pups are usually left scattered about the cage (or birth area) until parturition is complete.

Nursing

After all the pups have been delivered and cleaned the female will gather them together in a pile, arrange the nesting material about them, and will then begin to nurse. The commencement of nursing is accomplished by the mother crouching close over the pup pile. The pups react by searching the mother's abdomen until each has attached to a distended nipple, at which time the suckling responses begin. Occasionally, nursing may be observed even before parturition is complete if the delivery of the pups is slow, but such instances are rare.

Retrieving

If the pups should roll out of the nest, or propel themselves out, or be taken out, the mother will most likeIy retrieve them immediately or a short time after their removal. In the laboratory, retrieving tests are conduct- 
ed in the following way. The female is taken from the cage and some, or all, of the pups are removed from the nest and placed at other parts of the cage. When the mother is reintroduced into the cage she usually examines the empty nest first and then begins "searching" (i.e., examining by way of sniffing) the cage. At the time she comes upon a pup, or group of pups, she will examine it by way of sniffing it vigorously. At this point, she may, or may not, retrieve the pups (i.e., carry them, in her mouth, back to the nest). Most often she will examine the cage thoroughly before retrieving responses are initiated. After she identifies the cage and pups as her own, she will quickly retrieve the pups, one at a time, and place them back in the nest.

All of the behaviour patterns described above occur fully developed in the primiparous rat, and it seems to make no difference whether the female has been reared singly or in a group.

\section{Grooming}

Rat grooming is readily observable and constitutes a major activity in the daily routine of the animal. There are three distinct activities which comprise grooming beha- 
viour. These are: hind-foot scratching, rapid biting, and self-licking.

Hind-Foot Scratching

In this activity the claws of one hind foot are used, with rapid strokes, to scratch a particular part of the body. After hind-foot scratching, the claws are usually licked clean. Hind-foot scratching occurs spontaneously, is directed at one spot only, and ceases after a short interval.

Rapid Biting

This type of oral grooming behaviour is directed at a discreet spot on the body that is accessible to the front incisors and mouth. The activity consists of very rapid biting of the spot and this response, too, occurs spontaneously, is directed at one spot only, and ceases after a short interval.

Self-Licking

Self-licking constitutes the vast majority of grooming behaviour. The normal pattern of self-licking grooming is as follows. First, the animal assumes a "crouch" position by squatting on its hind legs and using the tail as a 
support. The forepaws are then brought up to the mouth and licked with rapid, vigorous, tongue strokes. A short period of this behaviour is followed by brushing of the head in which each of the forepaws is rubbed against the lateral side of the head, beginning at the base of the ears and ending at the nose. These head-brushing forepaw strokes are quite rapid. During the period when the rat is thus rubbing its head it may or may not suspend the licking movements of the tongue. The forepaw-licking, head-brushing sequence is known as "face-washing". Several alternate periods of forepaw-licking and head-brushing may occur before attention is turned to other parts of the body. Immediately after a period of face-washing, the animal usually bends over and licks its chest. After upper abdomen cleaning, it licks, in succession, first one side of the body and that side of the back, and then the other side of the body and back. Finally, it licks the lower abdomen (anogenital area) and the base of the tail. The rat may conclude the grooming episode at that point, or it may indulge in another short period of face-washing and then terminate grooming. Face-washing does not lead inevitably to body licking, and isolated parts of the body may be licked spontaneously; but the typical 
grooming sequence is as described above.

Self-licking is roughly analogous to human washing, while hind-foot scratching and rapid biting appear to serve the purpose analogous to human scratching. 
CHAPTER III

METHODOLOGY

\section{General Procedures}

The design of this experiment calls for the rearing of four groups of collared subjects (E1, E2, E3, and E4) and an uncollared control group (Cl). The collars of EI subjects were designed to prevent both body-licking and collar-licking. The E2 collars prevented body-licking but permitted collar-licking. The E3 collars permitted bodylicking but prevented collar-licking, while the E4 collars permitted both body-licking and collar-licking. The control group (Cl) received treatment identical to the $E$ group subjects except that $c l$ animals were not collared.

subjects

Fifty-six female rats of the sprague-Dawley strain, taken from the University of Windsor colony, served as subjects. It was anticipated that it would be physically impossible for the experimenter to handle the 56 subjects of the study on one occasion. Consequently, the animals 
were processed in two separate batches, the second batch $(N=22)$ being started 26 days after the start of the first batch $(N=34)$. At 21 days of age the $S s$ were weaned and randomly assigned to one of the five treatment groups. At the same time, they were placed in individual home cages and had fitted about their necks a collar of the type appropriate to their group. Collars were replaced with larger sizes as individual growth demanded.

Throughout the experiment the ss were individually housed in standard 10" $\times 7^{\prime \prime} \times 7^{\prime \prime}$ stainless steel cages (i.e., stainless steel sides and back with half inch mesh on the floor and front). The cages had plexiglass lids to permit direct overhead observation. Food and water were available at all times. All procedures and measures were carried out in the same room in which the $s$ s were housed. The room was large, well ventilated, and was maintained on an approximate 12-hour light-dark cycle, except as otherwise noted.

\section{Collar Preparation Procedures}

The most critical factor in this study is the collar, both as regards its design and the material of which it is made. An ideal collar would provide complete pro- 
hibition of mouth-body contact while offering no hinderance to normal locomotion. A small pilot study had shown that the cone-shaped collar used in this experiment (as against the flat type used by Birch and Christophersen and Wagman) appeared best able to meet these requirements. The cone shape is made by taking a flat type collar of appropriate size and cutting a wedge out, such that when the ends are joined, a cone-shape results. (A detailed presentation of the construction method, and the various sizes used, can be found in Appendix A.) The collars were constructed of a rubber gasket material, which is $1 / 16$ of an inch in thickness and is dull, brick red in colour. of the materials originally tested (which included asbestos, plastic, tephlon, and other grades of gasket rubber) it best fulfilled the requirements of being light, pliable, strong, non-toxic, and tastefully inoffensive to the animals.

Subject Treatment Groups

A summary of the subject group treatments is presented below in Table 1. It can be seen that two of the treatment groups (E3 and E4) required collars that would permit body licking. This possibility was obtained by cutting a notch, in the shape of an inverted $U$, in each 
E3 and E4 collar. The notch allowed the $s$ to lick any part of its body at will. The ss were observed to adapt quickly to the collar and become quite efficient in manipulating the position of the notch so as to facilitate body-1icking responses. (see Figure 1 in Appendix B.) It can also be seen that the ss of two of the treatment groups (El and E3) were prevented from licking their collars. Collar-licking was prevented by coating the inside surface of the collar with a substance called "Thum". Thum is a clear, reddish commercial preparation designed to be applied to the fingers of children to inhibit chronic nail-biting and thumb-sucking. Thum was selected from among several similar commercial preparations on the basis of its effectiveness in inhibiting oral manipulation (by pilot study rats) of objects coated with it. Thum was applied with a cotton swab to the interior surface of the collar from the outer circumference to within a quarter inch of the inner circumference. Each of the El and E3 collars was given five coats of Thum prior to use. It was noticed that the first and second coats were immediately absorbed by the material. The third, fourth, and fifth coats remained on the surface and formed a glaze when dry. 
Table 1

Group Treatments

\begin{tabular}{|c|c|c|c|}
\hline Group & Collaring & Body Licking & Collar Iicking \\
\hline E1 & collared & Denied & Denied \\
\hline $\mathrm{E} 2$ & collared & Denied & Permitted \\
\hline E3 & collared & Permitted & Denied \\
\hline E4 & Collared & Permitted & Permitted \\
\hline Cl & Uncollared & Permitted & - \\
\hline
\end{tabular}

Impregnation Procedures

When the Ss approached adulthood, consideration was given as to the most efficient method of impregnation. Christophersen and Wagman had reported that a male rat, when introduced to a collared female, tended to disfigure and remove the collar. Since it was imperative that conception occur and that the collars remain in place, it was decided to limit the time of male-female pairing. Hence, daily vaginal smears were obtained of all females. The number, type, and condition of the cells that make up the vaginal smear provide a fairly accurate reflection of the progress of the estrus cycle. The period of estrus can be detected by a microscopic examination of the daily vaginal smear. Thus, the time needed for copulation pairing, and 
the probability that the collars would be disfigured or removed, were reduced. A detailed presentation of the physiological processes surrounding the estrus cycle can be found in Zarrow (1964), Turner (1949), and Grollman (1947)

In the mature rat, it is found that estrus (psychological receptivity to copulation), and ovulation (biological receptivity to impregnation), normally coincide. They are, however, under the control of different hormones and either may occur in the absence of the other, although this is reputed to be a rare occurrence. It was suggested to the author (Gilman, personal communication) that the mere taking of the smear (i.e., the trauma associated with the procedure) may very well disrupt the animal's cycle so as to either retard or accelerate the passage of the cycle phases. With this consideration in mind, vaginal smears, beginning at 101 days of age, were obtained for each subject over four consecutive days prior to the actual initiation of mating. (A detailed presentation of the procedure used to obtain the vaginal smears can be found in Appendix c.) Beginning on the fifth day, each animal judged to be in estrus, or proestrus (the preestrus phase), was mated that night (i.e., a male was put 
into her cage for the 12 hours from $7-8$ p.m. to $7-8$ a.m.). An animal was judged to have conceived if, on the day following a mating, sperm cells were present in the vaginal smear, after which smearing was discontinued.

The above procedure was continued until all subjects were judged to have conceived or had had four matings. Any subject that did not conceive in four matings was rejected from the experiment on the assumption that she never would conceive under the particular set of procedures and circumstances that the experiment imposed.

Each collared $S$ was routinely fitted with a new collar (of the same type as she had been wearing) on the day she was judged to have conceived.

Pre-Parturition Procedures

It is essential to the design of this experiment that all collars be removed before litter delivery begins. If this had not been done, inadequate maternal behaviour may then have been ascribed to interference with the parturition process itself, rather than the self-licking deprivation that resulted from being collared (in the El and E2 groups).

In anticipation of the imminent delivery of their

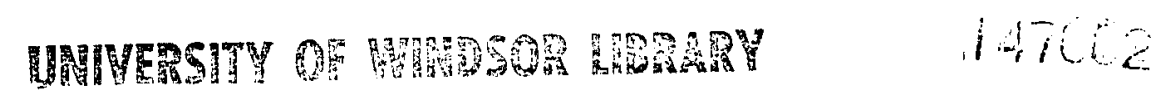


litters, all collared ss were decollared at 6:00 p.m. on the 21st day of pregnancy (except one El $S$ who appeared ready to deliver at any moment and was decollared at 2:30 p.m.). That is, had they conceived exactly at midnight on the night of mating they would have been precisely 21 days pregnant at midnight of the day of decollaring. (Twentyone days is the normal gestation period in rats.) since it is difficult to tell just when parturition is likely to occur, it was decided to have uniformity in decollaring, rather than to risk the onset of parturition with the collar still in place. As it turned out, one $E 4 \mathrm{~s}$ had to be rejected from the experiment for this reason (she began to deliver before 6:00 p.m. of the 2lst day, i.e., with her collar still in place).

At the same time as they were decollared, all ss were provided with a packet of nesting material (14 grams of shredded newsprint), and a quarter-inch mesh insert on the cage floor. The nesting material packet was suspended from one upper corner of the cage, using the weight of the plexiglass lid to hold it in place until the $\mathrm{S}$ had pulled it into the cage. A quarter-inch mesh insert was provided for an expectant female to prevent the new-born pups from falling through the half-inch mesh cage floor. 
Procedure at Parturition

Since pup cannibalization was always a possibility it was necessary that an observer be present at all deIiveries. consequently, a twenty-four hour watch was maintained on all subjects throughout the parturition period. An accurate record was thus obtained of the time of delivery (important for the timing of later measures) and the number of pups born. During this period the experimental room was continually illuminated.

\section{Measures}

Weights

All Ss were weighed weekly (beginning on the first day of the experiment) until they had conceived, after which they were weighed every two days, beginning on the first through to the twenty-first day of pregnancy. The weights were taken to provide an assessment of the effects of the various collaring treatments on the general health of the Ss.

Abdominal-Genital Cleanliness Measure

A measure was taken, referred to as the abdominalgenital cleanliness measure, to provide a quantitative assessment of the effectiveness of the unnotched collar in 
preventing, and the notched collar in permitting, bodylicking. These observations were taken when batch 1 ss were 123 days old and batch 2 ss were 97 days old. The body area under consideration was the lower abdomen, extending from a point at the middle of the abdomen to the anus and bounded on each side by the rear leg pit. An independent judgement by two qualified raters was obtained on each animal. The Ss were presented singly, in random order, and simultaneously to the two judges, ensuring that only the portion of the animal's body under consideration was visible. The juages could not see whether the $s$ was collared or not; and if collared, whether the type was of a notched or unnotched variety. Each juage was required to rate each $\mathrm{S}$ on a four-point scale as follows: 1 =very clean, 2 =quite clean, 3=dirty, and $4=v e r y$ dirty. The analysis was carried out on the mean of the two judgements. (Inter-judge reliability $=+.92$ )

Eighty-Fifth Day Licking Behavioux Measure

At the age of eighty-five days, licking behaviour observations were started and continued for four consecutive days. These observations were intended to provide a quantitative assessment of the effectiveness of the col- 
lars in preventing body-licking and of Thum in preventing collar-licking. A special observation box was constructed (See Appendix D) which provided both a direct frontal view and also, by way of an inclined mirror, a direct vertical view of the $S$ from underneath. This arrangement was extremely effective in observing licking behaviour despite the presence of the collar. The observations were carried out with the room darkened, except that enough daylight was allowed to enter through the window as would permit the experimenter to move about unobtrusively. Each observation period was 10 minutes long and the observation order was systematically varied over the four days, so as to rule out any possible temporal or order effects. Each $S$ was taken from its cage, carried by the experimenter (E) to, and placed in, the observation box. Aftex 10 minutes had elapsed the $\mathrm{E}$ returned the $s$ to its cage, noted the measurement that had been taken, and began with the next $s$. During the four days on which observations were taken, the Ss were not handled on that day prior to being put by the $\mathrm{E}$ into the observation box.

Since the collar restricted licking behaviour only as regards self-licking, these observations were a measure 
of the extent to which the various experimental treatments had altered the normal grooming pattern as described in chapter II. The measure is defined as the duration of activities wherein licking movements are judged to be directed at some part of the body. It was a direct measure (timed to the nearest second by a stopwatch) of the time spent grooming, or attempting to groom, except that hindfoot scratching and rapid biting were not scored. It will be remembered from Chapter II that licking movements of the tongue may or may not be suspended during head-brushing. The measure taken here was the length of the grooming episode that involved licking movements, not the duration of the movements themselves. The statistical analysis was computed on the mean of the four consecutive daily measures.

Maternal Efficiency Measures

When the pups of the parental population were one day old (defined as the period from 24 to 36 hours after birth), and five days old (the period from 120 to 132 hours after birth), a retrieving test was conducted on each mother and her litter. The following procedure was used. The cage was slid open (pulled forward), the female removed 
and placed in a covered pail. The live pups were then removed from the cage, counted, and examined to determine the general health of each. The litter was then weighed and the mean weight of the pups recorded. Any dead pups were removed from the cage at this time. The pups were then replaced in the cage, in a pile, in that front corner of the cage that was farthest from the nest centre. Since the $\mathrm{E}$ had arranged the lighting such that a shadow was cast in the back portion of the cage, the nests were invariably located in the rear of the cages. After having replaced the pups in the manner described above, the $\mathrm{E}$ then pushed the cage shut and slid open the plexiglass lid about half way. The mother was then returned to the cage through this top opening. She was lowered into the cage and released directly over the nest centre, facing a rear corner of the cage i.e., with her back to the pup pile. The plexiglass lid was immediately slid back into place. A stopwatch was started simultaneously with the female's release and stopped when she made contact with the pups. The female was given 10 minutes to retrieve the pups and the percentage retrieved in that time was recorded. A pup was considered to have been retrieved when the female picked it up and moved it from where the $\mathrm{E}$ had placed it, 
whether or not it was actually returned to the nest. Inasmuch as Birch had noted that retrieving behaviour was absent or deficient in his experimental Ss, it was hoped that this measure would provide an accurate reflection of maternal competence. Specifically, two measures were taken; first, the percentage retrieved within 10 min. after the female was reintroduced into the cage, and second, the "contact latency", or amount of time in seconds from reintroduction of the mother to pup contact, as described in chapter II. The rationale for this latter measure was that a good mother should make contact with her pups more quickly than would a poor mother. If the sniffing activity of the female upon reintroduction (described in Chapter II) represents a genuine searching for the pups, then the measure can be assumed to be a valid index of maternal efficiency. If the sniffing activity represents an exploratory response, elicited by novel stimuli (the empty nest and the movement of the cage Iid), then the measure is valid on the basis that a better mother would be "distracted" by these stimuli for a shorter period of time. (A considerable amount of urination and defecation takes place during the short interval of separation from the pups. One may therefore presume that 
such separation is a "traumatic" experience and that the female re-enters the cage in a highly motivated state.)

Final Measures

The mean weight of the pups of each litter was obtained again when the litters were 14 days and 21 days of age. The weighing of the litters at 21 days of age, and counting the number of survivors in each, was the final measure taken and represented the termination of the experiment. 
CHAPTER IV

\section{OBSERVATIONS AND RESULTS}

The contents of this chapter are presented in two parts. These are; the presentation of some supplementary observations, and a statement of the results of the statistical analyses of the measures taken. The supplementary observations are presented first because they provide a perspective against which the results can be best understood. In the case of the eighty-fifth day licking measure, a description of the observations, presented below, is prerequisite to an understanding of the statistical data.

\section{Part I : Supplementary Observations}

In every experinent with animal (and human) Ss, it is expected that some of the original population will be lost for a variety of reasons. Also inherent in animal research is the appearance of quite unexpected, and thereby uncontrolled, behaviour reactions. Finally, even the best-planned procedures can be confounded by unforeseen, 
uncontrolled, factors. The present study is no exception. This is not surprising when it is realized that some Ss will be exposed to rather severe treatments for long periods of time, and that some intricate procedures will be undertaken. The most pertinent of these "complications" will be discussed below under the following headings: subject Survival, Neck Soreness, Grooming Behaviour Modifications Associated with Collaring, Vaginal Smears, and Retrieving Behaviour Measures.

subject survival

Complete data were obtained on only 30 of the initial compliment of 56 subjects. In all, ten E1, five E2, three E3, six E4, and two Cl Ss were eliminated from the experiment for a variety of reasons (See Appendix E).

Neck soreness

Mention must be made of the physical injury to the neck that many of the collared animals suffered. The first consequence of collaring was that, as expected, the hair wore off about the neck in approximately one week. Soreness, as described below, could occur any time thereafter and from one week on, all collared ss were examined regularly for neck soreness. The soreness always 
occurred underneath the neck in the throat area. It appeared to be generated by the animal's posture during sleep and resting periods. The animal's sleeping position always resulted in the collar bearing upward on the throat. The skin would thus be pressed against the collar's edge for long periods of time and, as a consequence, would blister. The development of neck soreness was not confined to any collar size or type. Also, it made no difference whether the collar was loose or tight, the sleeping posture being the same in either case. No treatment was found effective in eliminating this condition since, if one sore healed, another usually developed. The most effective treatment was medicated talcum powder (of the type used for infants), applied liberally and massaged into the sore area. The severity of this condition varied from individual to individual; several ss never had neck soreness while a few were so severely affected they had to be sacrificed. The condition invariably cleared up within a few days after decollaring. It was thereby assumed that neck soreness did not represent a permanent deterioration of the ss' general health. 
Grooming Behaviour Modifications Associated with Collaring Notched Collar Type. The E3 and E4 subjects were observed to be very efficient in manipulating the position of the notch in their collars so as to facilitate grooming responses. The grooming behaviour exhibited by these ss was almost identical to that of uncollared animals (see chapter II, page 17). The grooming episode would begin in the crouch posture with the forepaws being brought up into the notch and licked. The forepaws would then be drawn back and the collar would be brushed in precisely the same manner that uncollared animals would brush their heads. These collar-brushing strokes would begin at the base of the col$\operatorname{lar}$ (inner circumference) and end at the outer circumference. After a short period of this behaviour, the $\mathrm{s}$ would lick its abdomen, sides, back, etc., through the notch, just as would an uncollared animal (See Figure 2 in Appendix F). During the period of collar-brushing, as for uncollared animals during head-brushing, the licking movements of the tongue may or may not be suspended.

Unnotched Collar Type. An unusual pattern of grooming behaviour was observed in every El and E2 subject. It may be described as the elicitation of the routine grooming responses in the absence of any licking contacts. The El and E2 
Ss would begin a grooming episode in the standard crouch position (see Figure 3 in Appendix F). The forepaws would be brought up under the collar and the animal would attempt to lick them (See Figure 4 in Appendix G), but licking contact never occurred, either with the forepaws or the intervening collar. A short period of this behaviour was followed by collar-brushing (See Figure 5 in Appendix G) exactly as described above for the notched collar Ss. The pseudo-face-washing sequence would most often constitute the entire grooming episode. Only on about half the occasions would E1 or E2 Ss turn their attention to the rest of their bodies. When this did occur, the same postural and positional routine was followed as described above for notched collar and uncollared ss. Licking movements of the tongue would be directed at the abdomen, sides, back, etc., but contact never occurred either with the body or the collar (See Figure 6 in Appendix H). The absence of collarlicking was further checked at the end of each observation session by examining the collar to see if there was any saliva on it. The collars were never found to have a moist spot. This unique activity, of eliciting grooming responses without making any licking contacts, will henceforth be referred to as "Phantom" grooming. 
No differences were observed in the "Phantom" grooming of E1 versus E2 subjects. "Phantom" grooming was observed to closely resemble the grooming of notched collar and control ss in that the amount varied from day to day and from individual to individual. "Phantom" grooming was observed in a notched collar $s$ on one occasion and endured for three seconds only.

All collared Ss were observed to scratch their collars as well as their bodies. The notched collar ss tended to lick the hind claw through the notch (see Figure 7 in Appendix H). The unnotched collar Ss tended to direct "Phantom" licking responses at the hind claw (presumably on the basis of proprioceptive cues), without making contact with either the claw or the collar (see Figure 8 in Appendix I). Hind-claw licking, or the attempt, was included in the eighty-fifth day licking behaviour measure. It was observed that occasionally an E1 or E2 subject would make a mouth-body licking contact. These contacts were made with a hind paw or the tail and invariably occurred in the following manner. The animal would be engaged in vigorous sniffing of the observation cage floor (urination was a frequent occurrence during the observation periods so olfactory stimuli were abundant) and, 
in doing so, would back itself up against a wall or corner. In this position, and still sniffing, the animal would find itself with its nose very close to or touching a hind paw. When this happened there would always be a brief ( 1 to 2 sec.) licking contact with the hind foot. such licking was also, of course, included in the eighty-fifth day licking behaviour measure.

\section{Vaginal smears}

The technique of judging whether or not impregnation had occurred during a mating experience, by way of the detection of sperm cells in the vaginal smear, was found not to be as reliable a method as had been expected. Six Ss were rejected (See Appendix E) as having failed to conceive in four matings, when, in fact, five of the six ss had been impregnated. On the other hand, five ss were judged to have conceived but were not pregnant. These were probably instances of the occurrence of estrus without coincident ovulation.

Retrieving Behaviour

Unfortunately, it soon became clear that the home cage was too small to provide an adequate test of retrieving behaviour when the pups were five days old. By this 
time, the pups were large and agile enough to move about the cage quite freely. consequently, on several occasions, some pups had crawled back into the nest before the mother had had a chance to retrieve them. When this happened the mother was considered to have retrieved those pups. Any pup that had to crawl back on its own, after the mother had retrieved the rest, was not considered to have been retrieved. Occasionally, when the mother was selecting a pup to retrieve, another would attach to a nipple and would be dragged back into the nest. Such pups were also considered to have been retrieved.

\section{Part II : Results}

Before presenting the main findings, a few remarks are in order concerning the variance in the number of $\mathrm{Ss}$ involved in each measure and the statistical methods employed in the analysis of the data. As mentioned above, some subjects had to be discaxded for various reasons (see Appendix E). Therefore, the analysis of the raw scores for any given measure was carried out on the following basis. The size of each group was reduced, by random elimination of the appropriate number of Ss, to the size of the smallest group on which data were available. This method prom 
vided for an equal number of $\mathrm{Ss}$ in each group and afforded a more reliable statistical assessment of the data. The maximum number of observations for any measure was 40 ( $5 \times 8$ ) because the $\mathrm{Cl}$ group at no time had more than eight members. The number of observations for other measures became smaller as the experiment progressed, simply because of the availability of a smaller number of Ss. The internal consistency of the data analysis was controlled, however, in that all analyses, having the same number of observations, were done on the same subjects.

The measures were assessed for statistical reliability by a simple analysis of variance technique. If a significant F-ratio was obtained (probability less than five per cent), the Duncan New Multiple Range Test (Edwards, 1960, p. 137) was applied to determine the location of the group differences. Additional analyses, using a correlation technique (Ferguson, 1959, p. 92), were computed on some scores to assess the reliability and validity of repeated measures.

The results of the analyses of the main measures axe presented below. 
Weight Measures of Parental Population at Twenty-one Days of Age

A summary of the analysis of variance of the weights of the subjects on the first day of the experiment is presented below in Table 2 (See Appendix $J$ for weight data).

\section{Table 2}

Analysis of Variance of Parental population Weights at TwentyOne Days of Age $(N=40)$

Source of Variation sum of Squares d.f. Mean Square $F$

\begin{tabular}{lrrrr}
\hline Between Groups & 81.75 & 4 & 20.44 & $.53 *$ \\
Within Groups & 1347.62 & 35 & 38.50 & \\
Total & 1429.37 & & & \\
\hline$* P>.05$ & & & \\
\hline
\end{tabular}

The F-ratio associated with this analysis is .53 which indicates that the Ss' initial weights did not differ significantly $(P>.05)$.

Weight Measures of Parental Population on the First Day of Pregnancy

A summary of the analysis of variance of the mother's weights on the first day of pregnancy is presented below in Table 3 (See Appendix $\mathrm{K}$ for Ss' weights). The F-ratio of 
3.71 indicates that there is a significant difference between the means of the five treatment groups $(P<.05)$.

Table 3

Analysis of Variance of Parental Population Weights on the First Day of Pregnancy $(\mathrm{N}=25)$

Source of Variation sum of squares d.f. Mean square $F$

\begin{tabular}{lrrrr}
\hline & 7533.84 & 4 & 1883.46 & $3.71 *$ \\
Between Groups & 10145.60 & 20 & 507.28 & \\
Within Groups & 17679.44 & & & \\
Total & & & & \\
*P $\mathrm{P} .05$ & &
\end{tabular}

The multiple comparisons of the treatment group means, applying the Duncan New Multiple Range Test, are shown in Table 4 below. It can be seen that the members of the $\mathrm{Cl}$ group were significantly heavier on the first day of pregnancy than were the members of the El, E2, and E3 groups. The CI Ss were not significantly heavier than the E4 Ss, nor did the E4 Ss differ significantly from the E1, E2, and E3 Ss.

Weight Measures of Parental Population on the Twenty-First Day of Pregnancy

A sumary of the analysis of variance of the mother's 


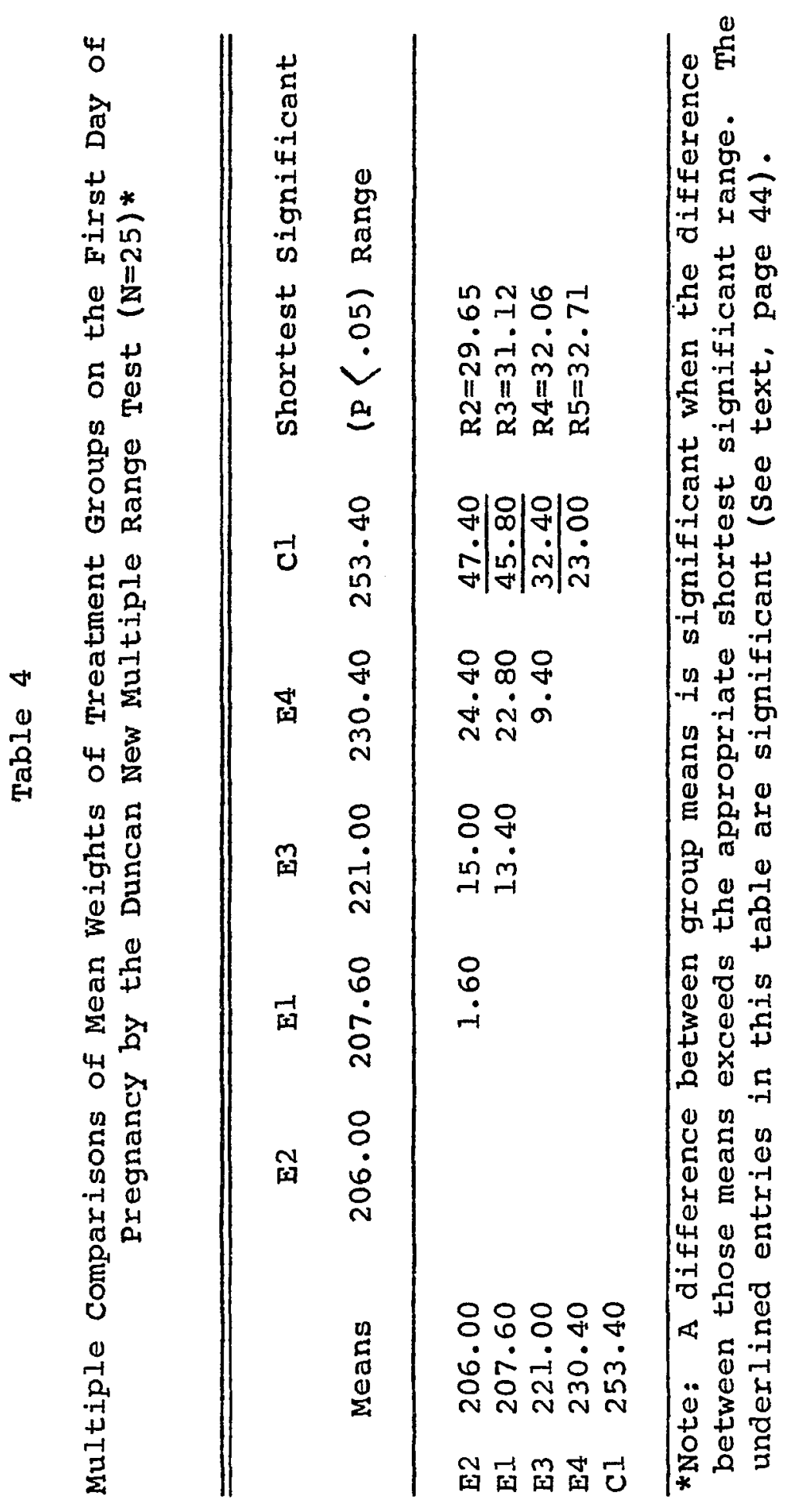


weights on the twenty-first day of pregnancy is presented below in Table 5 (See Appendix L for weights).

$$
\text { Table } 5
$$

Analysis of Variance of Weights of Parental Population on the Twenty-First Day of Pregnancy ( $N=25)$

Source of Variation Sum of Squares d.f. Mean Square $F$

\begin{tabular}{lrrrr}
\hline Between Groups & 3984.24 & 4 & 996.06 & $1.28 *$ \\
Within Groups & 16225.60 & 20 & 811.28 & \\
Total & 20209.84 & & & \\
\hline
\end{tabular}

$* \mathrm{P}>.05$

The F-ratio of 1.28 indicates that there were no significant differences in the weights of members of the various treatment groups on the twenty-first day of pregnancy

Abdominal-Genital Cleanliness Measure

A summary of the analysis of variance of the abdominal-genital cleanliness scores is presented in Table 6 below (See Appendix M for cleanliness scores). The large F-ratio of 28.00 indicates a highly significant difference between the groups. The results of the Duncan New Multiple Range Test, applied to these data, are given in Table 7. 
Table 6

Analysis of Variance of Abdominal-Genital cleanliness Scores $(\mathrm{N}=40)$

Source of Variation sum of Squares d.f. Mean Square $F$

\begin{tabular}{lrrrr}
\hline Between Groups & 24.63 & 4 & 6.16 & $28.00 *$ \\
Within Groups & 7.87 & 35 & .22 & \\
Total & 32.50 & & & \\
\hline$* P<.01$ & & & \\
\hline
\end{tabular}

It can be seen that groups El and E2 (which do not differ significantly from each other) were significantly less clean in the abdominal-genital region than were the E3, E4, and $\mathrm{cl}$ groups (none of which differed significantly from each other).

Eighty-Fifth Day Licking Behaviour Measure

Presented below in Table 8 is a summary of the analysis of variance of the mean number of seconds of grooming per observation period (See Appendix $N$ for data). The results show that the various treatment groups did not differ in the number of seconds (per ten minutes) spent grooming. 


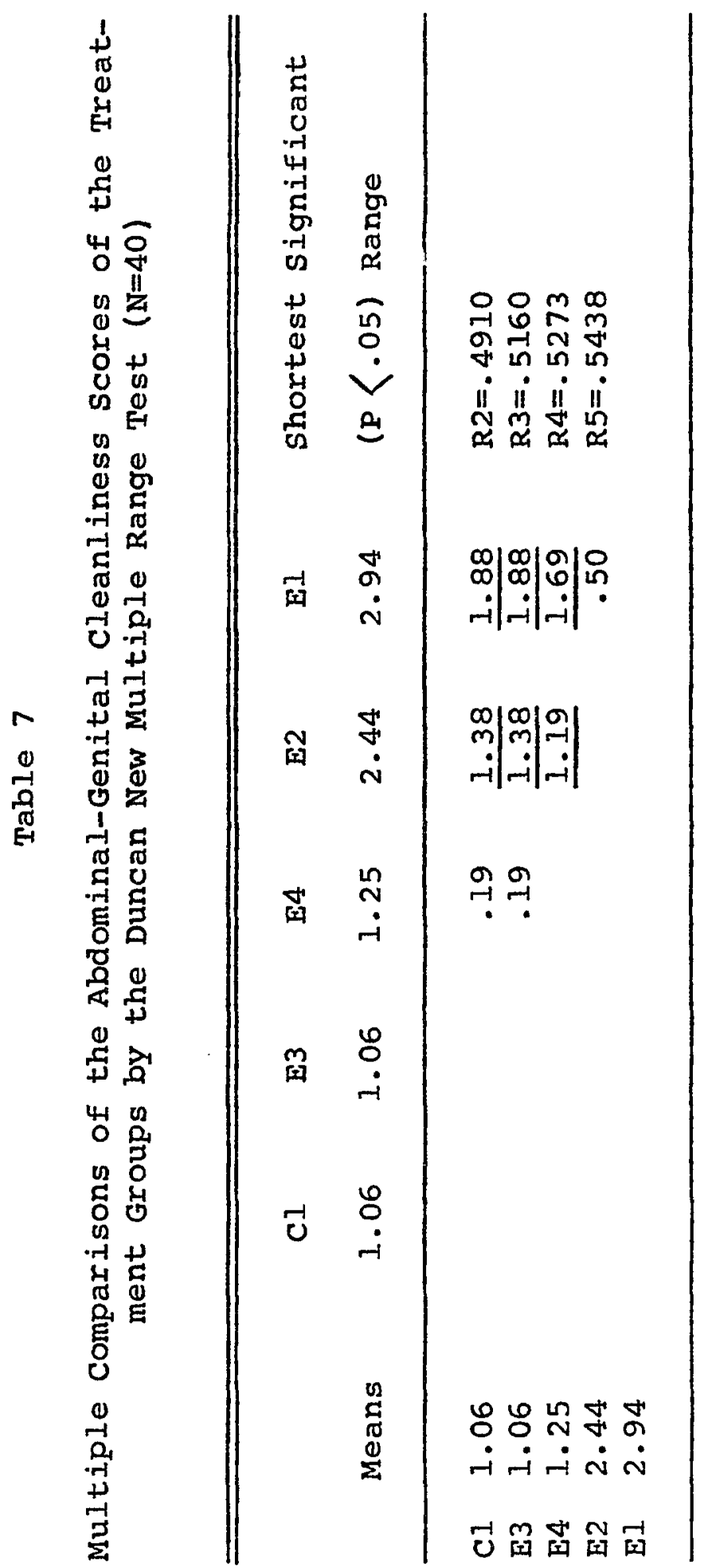


Table 8

Analysis of Variance of Eighty-Fifth Day Licking Behaviour Scores $(N=40)$

Source of Variation sum of squares d.f. Mean Square F

\begin{tabular}{lrrrr}
\hline & 656.19 & 4 & 164.04 & 2.11 * \\
Between Groups & 2716.06 & 35 & 77.60 & \\
Within Groups & 3372.25 & & & \\
Total & & &
\end{tabular}

*P> .05

Contact Latency on the First-Day Retrieving Test

A summary of the analysis of variance of the contact latency scores on the first-day retrieving test is given below in Table 9 (See Appendix O for scores).

Table 9

Analysis of Variance of Contact Latency Scores on the FirstDay Retrieving Test ( $N=25)$

Source of Variation sum of Squares d.f. Mean square F

$\begin{array}{lrrrr}\text { Between Groups } & 347.86 & 4 & 86.97 & .27 * \\ \text { Within Groups } & 6402.80 & 20 & 320.14 & \\ \text { Total } & 6750.66 & & & \end{array}$

$* P>.05$ 
The small F-ratio of .27 indicates that no difference existed between the contact latencies of the various treatment groups on the first-day retrieving test.

Contact Latency on the Fifth-Day Retrieving Test

A summary of the analysis of variance of the contact latency scores on the fifth-day retrieving test is presented below in Table 10 (See Appendix $P$ for scores).

Table 10

Analysis of Variance of contact Latency Scores on the FifthDay Retrieving Test $(\mathrm{N}=20)$

Source of Variation sum of squares d.f. Mean square $F$

\begin{tabular}{llrll}
\hline & & & & \\
Between Groups & 2702.80 & 4 & 675.70 & $3.63 *$ \\
Within Groups & 2790.25 & 15 & 186.02 & \\
Total & 5493.05 & & & \\
\hdashline$P<.05$ & & & & \\
\hline
\end{tabular}

The F-ratio of 3.63 indicates that a significant difference exists between the contact latency scores of two or more of the treatment groups. The multiple comparisons of these data, by the Duncan New Multiple Range Test, is presented in Table 11. It can be seen that the E4 Ss took significantly longer to reach their pups than did the E1, E2, 


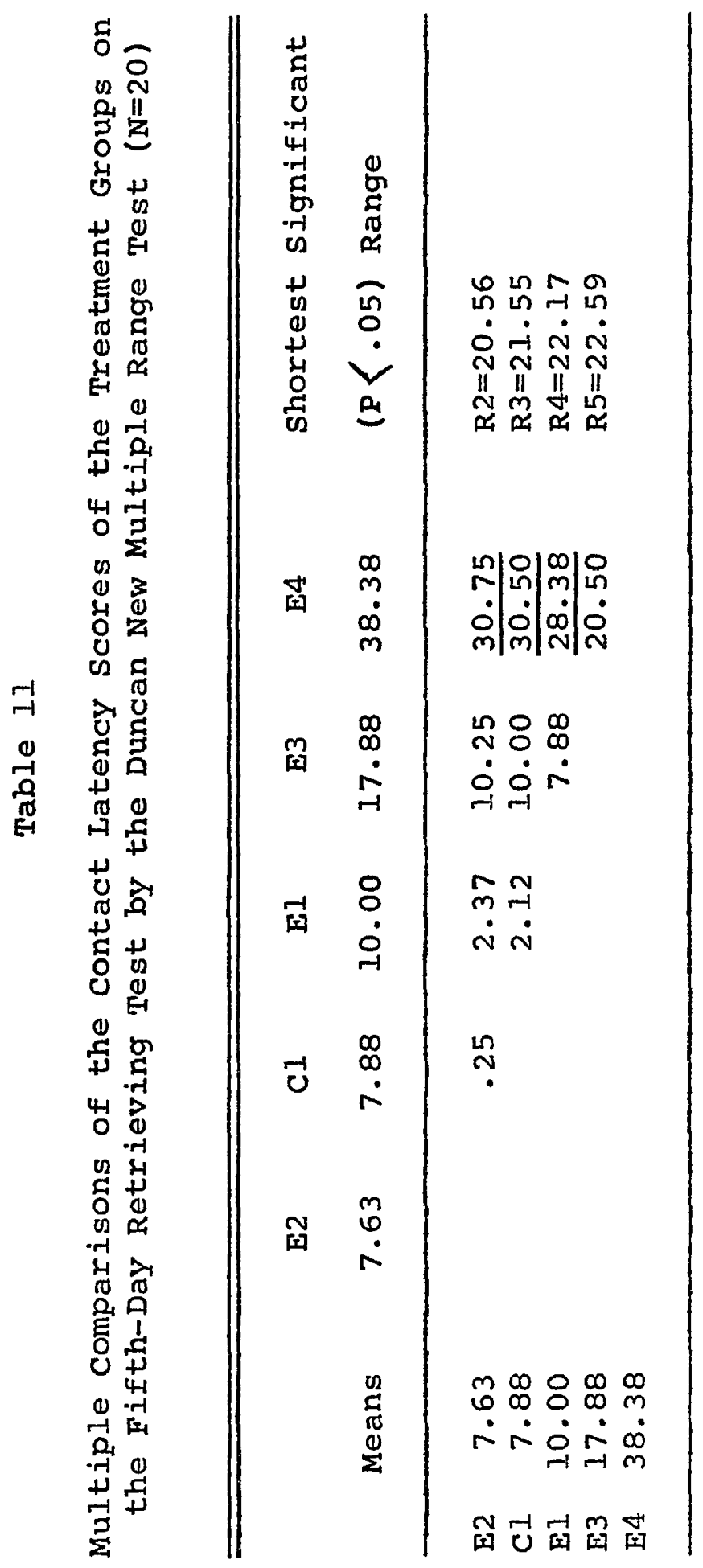


and $\mathrm{Cl}$ Ss. There was not a significant difference between the E4 and E3 groups or among the E1, E2, E3, and C1 groups. There appears to be no ready explanation for the results presented above in Tables 10 and 11 . These findings indicate that, on the fifth-day retrieving test, the E4 and E3 ss tend to be the poorest mothers (i.e., took the longest to make contact with their pups), yet these groups had the highest pup survival rates (See Table 14 below). The correlation coefficient calculated on the first-day and fifth-day contact latency scores was non-significant $(r=-.09, P) .05)$. The correlation coefficient of -.09 indicates that no relationship existed between the ss' first-day and fifth-day contact latencies. Therefore, the contact latency score cannot be regarded as a reliable indicator of maternal efficiency.

Percentage Retrieved on First-day Retrieving Test A summary of the analysis of variance of the percentage of pups retrieved on the first-day retrieving test is presented below in Table 12 (See Appendix Q for data). The F-ratio of .27 indicates that no difference existed in the percentage of pups retrieved by members of the various treatment groups on the first-day retrieving test. 
Table 12

Analysis of Variance of Percentage of Pups Retrieved on the First-Day Retrieving Test $(\mathrm{N}=25)$

Source of Variation sum of squares d.f. Mean square $F$

\begin{tabular}{|c|c|c|c|c|}
\hline Between Groups & 6400 & 4 & 1600 & $.27 *$ \\
\hline Within Groups & 12000 & 20 & 6000 & \\
\hline Total & 18400 & & & \\
\hline
\end{tabular}

$* P>.05$

Percentage Retrieved on Fifth-Day Retrieving Test

A summary of the analysis of variance of the percentage of pups retrieved on the fifth-day retrieving test is presented below in Table 13 (See Appendix $R$ for data).

Table 13

Analysis of Variance of Percentage of Pups Retrieved on the Fifth-Day Retrieving Test $(\mathrm{N}=20)$

source of Variation sum of squares d.f. Mean square $F$

\begin{tabular}{|c|c|c|c|c|}
\hline Between Groups & 2503.81 & 4 & 625.95 & $.26 *$ \\
\hline within Groups & 34125.64 & 15 & 2275.04 & \\
\hline Total & 36629.45 & & & \\
\hline
\end{tabular}


The F-ratio of .26 indicates that the members of the various treatment groups did not differ in the percentage of pups retrieved on the fifth-day retrieving teat.

Calculation of the first-day and fifth-day percentage retrieved scores yielded a non-significant correlation coefficient $(x=+.35, P) .05)$. The low reliability of this measure was most probably a function of the less than ideal conditions under which it was conducted (see text, page 41). The validity of this measure as an indicator of maternal efficiency must, therefore, remain an open question.

Pup Survival

The dependent variable in this study is, of course, the percentage of pups born to survive to weaning age as a function of the different treatments given to the parental population. In Table 14, below, is the number of pups per mother, of each parental group, to survive to criterion.

A summary of the analysis of variance of the percentage of pups born to survive till weaning age is presented in Table 15 (see Appendix S for data). 
Table 14

Number of Pups Per Mother to Survive to Twenty-One Days of Age by Parental Treatment Groups ( $N=30)$ Treatment Live Pups Group Delivered to survive to to complete Per Mother Weaning Age Experiment Per Mother

\begin{tabular}{lrll}
\hline E1 & 11.2 & 8.6 & 5 \\
$\mathrm{E} 2$ & 10.4 & 8.9 & 7 \\
$\mathrm{E3}$ & 9.9 & 9.0 & 7 \\
$\mathrm{E} 4$ & 11.6 & 9.0 & 5 \\
$\mathrm{C1}$ & 10.5 & 6.2 & 6 \\
\hline
\end{tabular}

Table 15

Analysis of Variation of Pup Survival Percentage ( $N=25)$

Source of Variation sum of squares d.f. Mean square $F$

\begin{tabular}{|c|c|c|c|c|}
\hline Between Groups & 922.13 & 4 & 230.53 & $.17 *$ \\
\hline Within Groups & 26697.85 & 20 & 1334.89 & \\
\hline Total & 27619.98 & & & \\
\hline
\end{tabular}

The F-ratio of .17 is non-significant from which it is concluded that the treatments administered to the mothers made no difference in the rates of survival, at least 
to weaning age, of the off-spring.

In addition to these main parameters a number of subsidiary measures were also analyzed statistically in order to ascertain which variables, main or subsidiary, show differences between treatment groups. These analyses and results are shown in Table 16 .

In summary, of all the data collected, the only variables, main or subsidiary, which show a significant difference between treatment groups are as follows:

(1) Parental Population Weights on the First Day of Pregnancy ( $P$.05).

(2) Number of Live Pups Delivered by Parental Population ( $P$.01).

(3) Abdominal-Genital cleanliness ( $\mathrm{P}$.01).

(4) Contact Latency on Fifth-Day Retrieving Test (P .05).

(5) Mean Pup Weight at Twenty-One Days of Age (P. .05).

These factors will be examined in the following section to see if they relate to pup survival percentage. Those factors which show no between treatment group differences will not be mentioned again in this thesis. 
Table 16

Analyses and Results of Subsidiary Measures

\begin{tabular}{|c|c|c|}
\hline Subsidiary Factor M & Method of Analysis & Statistical Result \\
\hline $\begin{array}{l}\text { No. of hrs. from } \\
\text { Decollaring to } \\
\text { Parturition }\end{array}$ & $\begin{array}{l}\text { Analysis of } \\
\text { Variance }\end{array}$ & Non-Significant \\
\hline $\begin{array}{l}\text { No. of Live Pups } \\
\text { Delivered }\end{array}$ & $\begin{array}{l}\text { Analysis of } \\
\text { Variance }\end{array}$ & $\begin{array}{l}\text { Significant }(P\langle .01) \\
\text { E4 litters }\rangle \text { than } C I \\
\text { and E2 litters. Els } \\
\text { and E3s }\rangle \text { than E2s. }\end{array}$ \\
\hline $\begin{array}{l}\text { Mean Pup weight } \\
\text { at one Day old }\end{array}$ & $\begin{array}{l}\text { Analysis of } \\
\text { Variance }\end{array}$ & Non-Significant \\
\hline $\begin{array}{l}\text { Mean Pup Weight } \\
\text { at 14 Days old }\end{array}$ & $\begin{array}{l}\text { Analysis of } \\
\text { Variance }\end{array}$ & Non-Significant \\
\hline $\begin{array}{l}\text { Mean Pup Weight } \\
\text { at } 2 I \text { Days old }\end{array}$ & $\begin{array}{l}\text { Analysis of } \\
\text { Variance }\end{array}$ & $\begin{array}{l}\text { Significant }(P<.05) \\
C l \text { Ss }>\text { than others. }\end{array}$ \\
\hline $\begin{array}{l}\text { No. of Mating } \\
\text { Experiences Required } \\
\text { to Impregnate } \\
\text { Parental Females }\end{array}$ & $\begin{array}{l}\text { Analysis of } \\
\text { Variance }\end{array}$ & Non-Significant \\
\hline $\begin{array}{l}\text { Percentage Weight } \\
\text { Increase During } \\
\text { Pregnancy }\end{array}$ & $\begin{array}{l}\text { Analysis of } \\
\text { Variance }\end{array}$ & Non-Significant \\
\hline $\begin{array}{l}\text { No. of Stillborn } \\
\text { Pups Delivered }\end{array}$ & $\begin{array}{l}\text { Analysis of } \\
\text { Variance }\end{array}$ & Non-Significant \\
\hline
\end{tabular}




\section{CHAPTER V \\ DISCUSSION}

\section{Interpretation of Results}

The purpose of this experiment was to rear groups of female rats under various degrees of self-licking deprivation. It was hypothesized that the more a female was deprived of the opportunity to perform self-licking responses the less adequate would be her maternal behaviour. It was further suggested (page 10) that, when deprived of the opportunity to perform self-licking responses, the Ss would lick their collars, and that collar-licking would serve as an effective substitute for self-licking upon which basis maternal behaviour could be mediated. Measures were designed to assess the effectiveness of the self-licking, and collar-licking, deprivation treatments. The measurement of maternal efficiency was evaluated through retrieving tests and the survival rates of the litters.

Several variables were identified in the last sec58 
tion which show significant between treatment group differences. They are:

(1) Parental Population weights of the First Day of Pregnancy.

(2) Number of Live Pups Delivered by Parental Population.

(3) Abdominal-Genital Cleanliness.

(4) Contact Latency on Fifth-Day Retrieving Test.

(5) Mean Pup Weight at Twenty-One Days of Age.

These factors, as they relate to maternal behaviour, will be discussed separately below.

Parental Population Weights on First Day of Pregnancy The periodic weight checks on each $S$ showed that, generally, the uncollared Ss (Cl group) tended to be heavier than any of the collared Ss. By the first day of impregnation, the uncollared Ss were significantly heavier than three of the collared groups and heavier, though not significantly, than the fourth collared group (E4). These weight differences probably resulted from a nourishment factor as the collar may have provided some mechanical interference with the procurement of food. If such was the case then, generally, the control ss were healthier at impregnation than the experimental Ss. This, in turn, would 
lead to the probability that the control $s$ would bring forth a larger and heavier litter, and would make a more efficient mother. The analyses of these data, however, do not support this contention. On the contrary, the cl mothers had the lowest pup survival rate, and did not differ from the other treatment groups with respect to the weight of the new-born pups (the factor of number of pups born to each $\mathrm{S}$ will be discussed below). Therefore, it must be concluded that, in this investigation, there is no relationship between the mother's weight at impregnation and her ability to rear a litter of pups.

Number of Live Pups Delivered by Parental Population The analysis of the number of pups born to each female showed that E4 litters were significantly larger than E2 and $\mathrm{Cl}$ litters. The EI and E3 litters did not differ from the $\mathrm{E} 4$ or $\mathrm{Cl}$ litters but were also significantly larger than the E2 litters. The Cl litters were the smallest in size, but, as noted above, the $\mathrm{cl}$ mothers were the heaviest in weight. Thus, the factor of mother's weight at impregnation seems unrelated to litter size as well. It might be expected that in litters of large size, the pup survival rates would be lower than in smaller litters as 
there would be more competitors for a limited amount of food. This, however, was not the case. The largest litters (E4) had the second highest survival rate while the smallest litters (E2) had the third highest survival rate. Therefore, it must be concluded that the factor of litter size was unrelated to pup survival rate.

\section{Abdominal-Genital Cleanliness}

The results of the analysis of the abdominal-genital cleanliness data indicate that the El and E2 Ss did not indulge in self-licking nearly to the extent that did E3, E4, and $\mathrm{Cl}$ Ss. The observations noted during the eighty-fifth day licking behaviour measure confirmed the experimental expectation that $\mathrm{EI}$ and $\mathrm{E} 2 \mathrm{Ss}$ made only rare body-licking contacts and no collar-licking contacts. On the other hand, E3 and E4 Ss made the normal amount of body-licking contacts. The effectiveness of the unnotched collars in preventing, and the notched collars in permitting, self-licking responses is, therefore, beyond question. Now, it is logical to argue that if the unnotched collars prevented body-licking, then according to the Birch, "relationship to the self", theory, the El and E2 Ss should have displayed the least efficient maternal behaviour. The re- 
sults obtained show that these mothers had as high pup survival rates as had mothers exposed to any of the other treatments. Therefore, it must be concluded that the present data do not confirm the Birch theory. In addition, as the E1 and E2 Ss were not observed to make any collar-licking contacts, the hypothesịs of the present investigation was not confirmed.

Contact Latency of Fifth-Day Retrieving Test The analysis of the contact latencies of the fifthday retrieving test shows that E4 Ss took significantly longer to reach their pups than did El, E2, and Cl Ss, yet the E4 litters had the second highest survival rate. The low reliability of this measure as an index of maternal efficiency has already been discussed (page 52). It may be concluded that no relationship exists between the mother's contact latency score and her ability to rear a litter.

Mean Pup Weight at Twenty-One Days of Age

The analysis of the pups' mean weights at weaning age revealed that, at this time, the Cl pups were significantly heavier than those of the other treatment groups. It might be expected that the heaviest pups would occur in

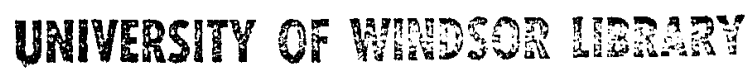


the litters with the lowest survival rates, inasmuch as the competition for the available food would be less in such litters. The heaviest pups (cls) did, in fact, have the lowest survival rate $(69.2 \%)$. However, the second heaviest pups (E3s) had the highest survival rate $(88.2 \%)$, and the lightest pups (E4s) had the second highest survival rate $(80.0 \%)$. On this basis it must be concluded that the factor of pup weight, at twenty-one days of age, was unrelated to pup survival rate.

Experimental Considerations

The stated intent of this study was to replicate the Birch and the Christophersen and Wagman experiments, in addition to having more refined procedures (more treatment groups and controls). These additions, it was expected, would verify the suggested source of the contradictory results obtained by Christophersen and Wagman compared to those of Birch. As the results discussed immediately above show, this expectation was not realized. Since the findings were negative, it is felt necessary, for completeness of exposition, to examine other possible sources of bias between the above mentioned studies and the present one. These will be discussed below under the following head- 
ings: Age of Collaring, Collar Material, Time of Decollaring, Collar Design, and Strain Differences.

Age of collaring

Birch does not report, nor did he reply to a direct inquiry, the exact age at which his experimental ss were collared. Christophersen and Wagman report that their experimental ss were collared at age 11 days $i . e ., 10$ days before normal weaning age. In this last mentioned study, it seems difficult to imagine that the mother would have tolerated such a device on members of her litter. The a1most certain attempts, by the mother, to remove the collars would constitute an extremely traumatic experience for the pups. An alternative possibility is that the pups were separated from their mothers at age 11 days, collared, and fed by hand until they had reached normal weaning age. This procedure would result in depriving the animals of considerably more than merely the opportunity to self-lick. In any event, the pertinent information on the subject was not reported by the authors and one can only speculate rather fruitlessly.

Therefore, it was decided, in the present research, that the most practical time at which to begin the experi- 
ment was when the Ss were 21 days of age. For the reason just stated, this would permit the most meaningful data to be collected. If the age of collaring is a significant factor in determining maternal efficiency, none of the studies conducted thus far, including the present investigation, have shown this to be so.

Collar Material

Birch does not report the type of material from which his collars were constructed. Christophersen and Wagman report that their collars were made of a rubber gasket material. The present experiment also utilized collars made of a rubber gasket material. It is unlikely, however, that the material used was identical in all three studies. It was speculated that different taste qualities of the colIar materials used may have contributed to the source of the discrepant results reported by Birch and by Christophersen and Wagman.

In this experiment, conditions were provided under which some groups of $\mathrm{ss}$ would be permitted collar-licking while other groups would be denied this response. These procedures, it was anticipated, would permit evaluation of the hypothesis that collar-licking may be an effective sub- 
stitute for self-licking. It was essential, therefore, that the collar material be tastefully inoffensive (i.e., to be licked or even chewed). The suitability of the collar material, in this respect, was established in pilot study animals, prior to the beginning of this investigation, i.e., samples of the material were observed to be quickly chewed and shredded by such animals. As was described in Chapter III (page 22), Thum was used to inhibit collarlicking by E1 and E2 Ss. It was observed that pilot study animals did not chew and shred samples of the collar material that had been coated with Thum.

The evidence showed that the ss of the uncoated collar groups (E2 and E4) reacted identically to their collars as did the Ss of the coated collar groups (EI and E3), i.e., none of the collared animals were observed to lick their collars. Therefore, whether or not collar-licking can substitute for body-licking, and thereby mediate maternal behaviour, must remain an open question.

Time of Decollaring

Both the Birch and the Christophersen and Wagman studies report that their experimental ss were decollared a few hours prior to parturition. As was stated in Chap- 
ter III (page 25), it was thought preferable in this study to decollar the Ss at a predetermined time, near the termination of pregnancy, rather than to risk the onset of parturition with the collars still in place. It was observed that $\mathrm{E} 1$ and $\mathrm{E} 2$ Ss gave typical grooming responses within minutes of being decollared. Parturition occurred from 18 to 44 hours after decollaring (over-all mean = 30.5 hours). It might be argued that this was time enough for the El and E2 Ss to acquire the learnings hypothesized by Birch as being essential to adequate maternal behaviour. on common sense grounds, it seems highly improbable that a behaviour so fundamental to the survival of the species could depend upon learnings so recently acquired. However, this is speculation only, and the importance of the time of decollaring of the animal, prior to parturition, remains to be demonstrated.

\section{Collar Design}

The use of the conical collar was an obvious departure in procedure as compared to the type used in either the Birch or the Christophersen and Wagman studies. In observations taken on pilot study animals, the conical collar design seemed much superior to the flat type in preventing 
self-licking and, at the same time, interfering least with normal ambulation. It represents, nonetheless, a difference which, as will be discussed below, may have contributed to the development of grooming responses and to have thus inEluenced maternal behaviour.

The analysis of the eighty-fifth day licking behaviour scores indicates that E1 and E2 Ss spent as much time in the performance of "Phantom" grooming as did E3, E4, and Cl Ss in normal grooming. It is not known if the experimental ss of either Birch or Christophersen and Wagman manifested "Phantom" grooming responses. It appears likely that the conical collar would tend to promote this activity more than would a flat type collar. The collar-brushing phase of "Phantom" face-washing (See Chapter IV, page 38) would be a much more difficult response to perform if the animal was wearing a flat type collar. As was noted earlier, face-washing often constituted the entire "Phantom" grooming episode. For these reasons, "Phantom" grooming, if it occurred at all, may have been unnoticed by Birch and Christophersen and Wagman. However, it would be premature, at this point, to speculate what relationship might exist, if any, between the mere elicitation of the grooming routine, "Phantom" or normal, and adequate maternal behaviour. 
Strain Differences

Neither Birch nor Christophersen and Wagman report what strain of laboratory rat they used as subjects in their experiments. The present investigation utilized subjects of the sprague-Dawley strain. Inasmuch as the response pattern under study in these three experiments is an instinctive behaviour, i.e., is assumed to be largely under the influence of inherited factors, the strain of animals used is a crucial variable. The agreement between the results of the present investigation and those of the Christophersen and Wagman study may be based on the possibility that the same rat strain was used in both researches. The possible procedural differences notwithstanding, Birch's results may be obtainable only on the particular strain of rats that he used. Such a genetic interpretation of the results of these three experiments is, however, pure speculation, and the importance of the factor of strain differences remains to be demonstrated. In summary, although the necessary conditions were provided to test the hypothesis that collar-licking may serve as an effective substitute for self-licking, the findings do not permit any firm conclusions to be drawn. However, the conditions necessary for an adequate test of 
the Birch "relationship to the self" theory were met. The results are in accord with those of Christophersen and Wagman. The pup survival rates in the Christophersen and Wagman study were $73 \%$ for the experimental and $75 \%$ for the control pups. In the present investigation the pup survival rates were as follows: $E 1=77.3 \%, E 2=78.0 \%, E 3=88.2 \%$, $E 4=80.0 \%$, and $\mathrm{Cl}=69.2 \%$. Both of these two sets of results tend to refute the Birch hypothesis that prior licking experiences, especially of the anogenital area, are fundamental to adequate maternal behaviour. 
CHAPTER VI

\section{SUMMARY AND CONCLUSIONS}

Four groups of female rats (E1, E2, E3, and E4), totalling $56 \mathrm{ss}$, were reared with rubber collars about their necks such that they were unable to lick and groom their bodies in a normal fashion. The El group collars prevented the occurrence of body-licking. In addition, these collars were coated with a bitter substance which it was expected would effectively inhibit collar-licking. The E2 group collars were identical to the El group collars except that they were uncoated. Thus, E2 group animals could lick their collars but not their bodies. The E3 group collars were notched in such a way that body-licking was possible. These collars were also coated with the bitter substance so that collar-licking would not occur. The E4 group collars were identical to the E3 group collars except that they were uncoated. The E4 group Ss could, therefore, lick their bodies and their collars. A control group (cl) was also reared under conditions identical to those of 
the above mentioned experimental groups except that $\mathrm{cl} \mathrm{Ss}$ were uncollared.

At twenty-one days of age the subjects were weaned, collared (except $\mathrm{Cl}$ Ss), and placed in individual cages. Upon reaching adulthood all ss were impregnated. The collars were removed a few hours prior to parturition. Measures designed to assess the effects of the collaring treatments (i.e., levels of licking deprivation) on the Ss' maternal behaviour were conducted. Prior to parturition, measures were conducted which were designed to assess the effectiveness of the collaring treatments in preventing selflicking and collar-licking.

In this experiment, it was hypothesized, based on the interpretation of a previous study (Birch, 1956), that selflicking experiences are crucial to the development of maternal responses. It was further hypothesized that collarlicking may serve as an effective substitute for self-licking and thereby mediate normal maternal responses.

The results indicate that none of the collared subjects resorted to collar-licking when denied self-licking. Thus, this hypothesis of the study was not confirmed. However, the Birch "relationship to the self" theory was empirically tested. The analysis of the number of pups born 
to survive to weaning age indicates that the ss which had been deprived of the opportunity to perform self-licking responses were as maternally efficient as those ss which had had unlimited self-licking opportunity.

It must be concluded, therefore, that adequate maternal behaviour is independent of the amount of prior self-licking experiences. 


\section{SUGGESTIONS FOR FURTHER RESEARCH}

A worthwhile contribution to the study of maternal behaviour would be the development of reliable and valid tests that would differentiate efficient from inefficient mothers (e.g., Moltz and Robbins, 1965).

Further investigation of the phenomenon of "Phantom" grooming is certainly warranted. The study of this schizophrenic-like caricature of normal grooming may provide insight into the nature of instinctive behaviours.

It is hoped that, in any future experiments which utilize a collaring procedure, the possible differential effects of various ages of collaring and times of decollaring will be explored.

Rat grooming behaviour, established before age 21 days, has proven itself to be an extremely durable response pattern. Further research into the ontogeny of rat grooming is definitely needed. 
APPENDIX A

Conical Collar Construction Method

The conical collar is shaped from a flat type collar, of appropriate size, by cutting a wedge out of the circumference and then joining the free ends. In this study 25 per cent (less a small amount necessary for stitching) was removed and the free ends were stitched together with nylon fishing line (See diagram below).

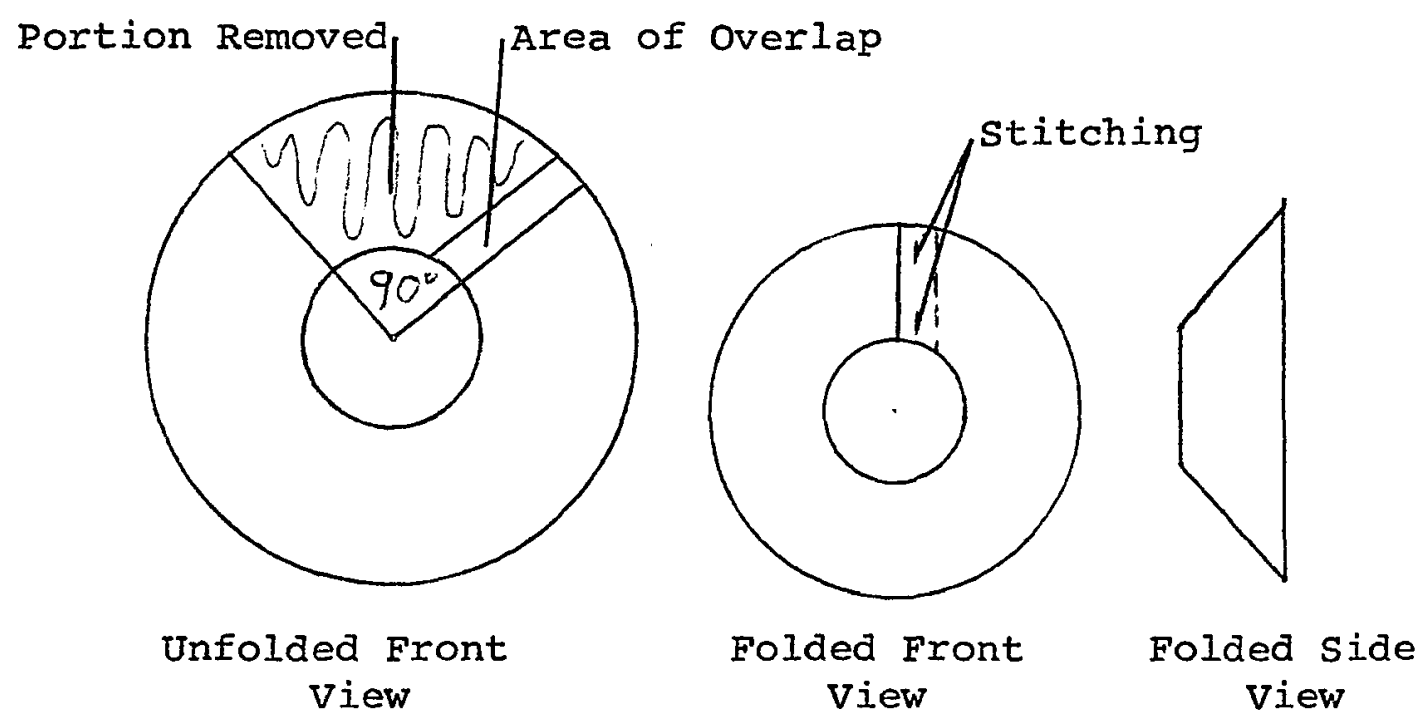




\author{
APPENDIX A (cont.) \\ Collar sizes and Weights
}

\begin{tabular}{|c|c|c|c|c|}
\hline $\begin{array}{l}\text { Folded } \\
\text { Inside } \\
\text { Diameter } \\
\text { (in.) }\end{array}$ & $\begin{array}{l}\text { Distance from } \\
\text { Inner to outer } \\
\text { Circumference } \\
\text { (in.) }\end{array}$ & $\begin{array}{l}\text { Approximate } \\
\text { Age Put on }\end{array}$ & $\begin{array}{l}\text { Weight of } \\
\text { Notched } \\
\text { Collar } \\
\text { (gm.) }\end{array}$ & $\begin{array}{l}\text { Weight of } \\
\text { Unnotched } \\
\text { Collar } \\
\text { (gm.) }\end{array}$ \\
\hline $9.75 / 16$ & $17.5 / 16$ & 21 days & 10.0 & 10.5 \\
\hline $11.25 / 16$ & $22.5 / 16$ & 32 days & 13.5 & 16.0 \\
\hline $12.75 / 16$ & $27.5 / 16$ & 43 days & 20.0 & 22.5 \\
\hline $14.25 / 16$ & $30.5 / 16$ & 56 days* & 24.0 & 28.5 \\
\hline
\end{tabular}




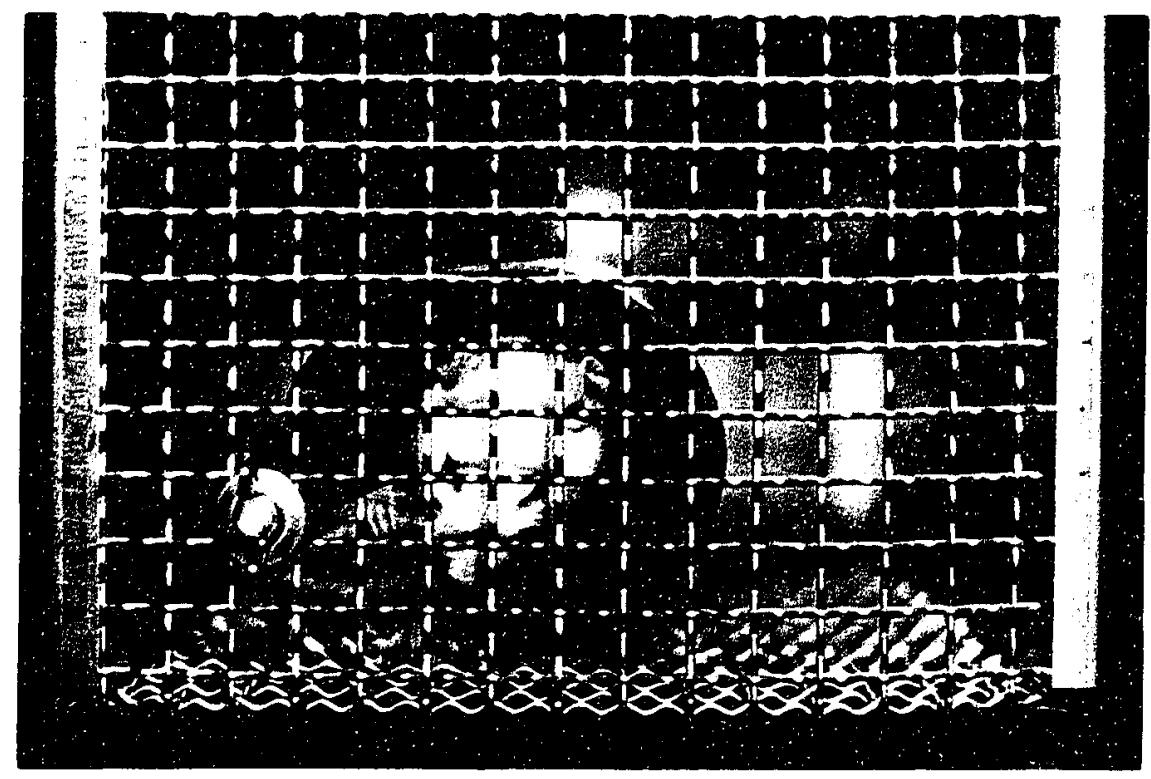

Figure 1. Self-licking by a notched collar subject. 


\section{APPENDIX C \\ Vaginal Smear Technique}

The smears were obtained at approximately the same hour each afternoon. The animals were not handled on that day prior to the taking of the smear.

First a clear cylindrical glass rod of about $3 \mathrm{~m} . \mathrm{m}$. in diameter was dipped into a bottle of distilled water and one or two drops of the water were placed in the centre of a clean microscope slide. The subject was then taken from its cage and held while the moist tip of the rod was inserted a distance of about $3 \mathrm{~m} \cdot \mathrm{m}$. into the vagina. The rod, in this position, needed only to be spun in the fingers-no probing or scraping was required. The rod having been withdrawn and the animal having been returned to its cage, the vaginal epithelial cells clinging to the tip of the rod can be readily transferred to the microscope slide by merely touching the tip of the rod to the drop of water on the slide and spinning the rod in the fingers. Photographs of rat vaginal smears (Zarrow, 1961, p. 26-27) were used in making a juagement of the estrus cycle phase. 


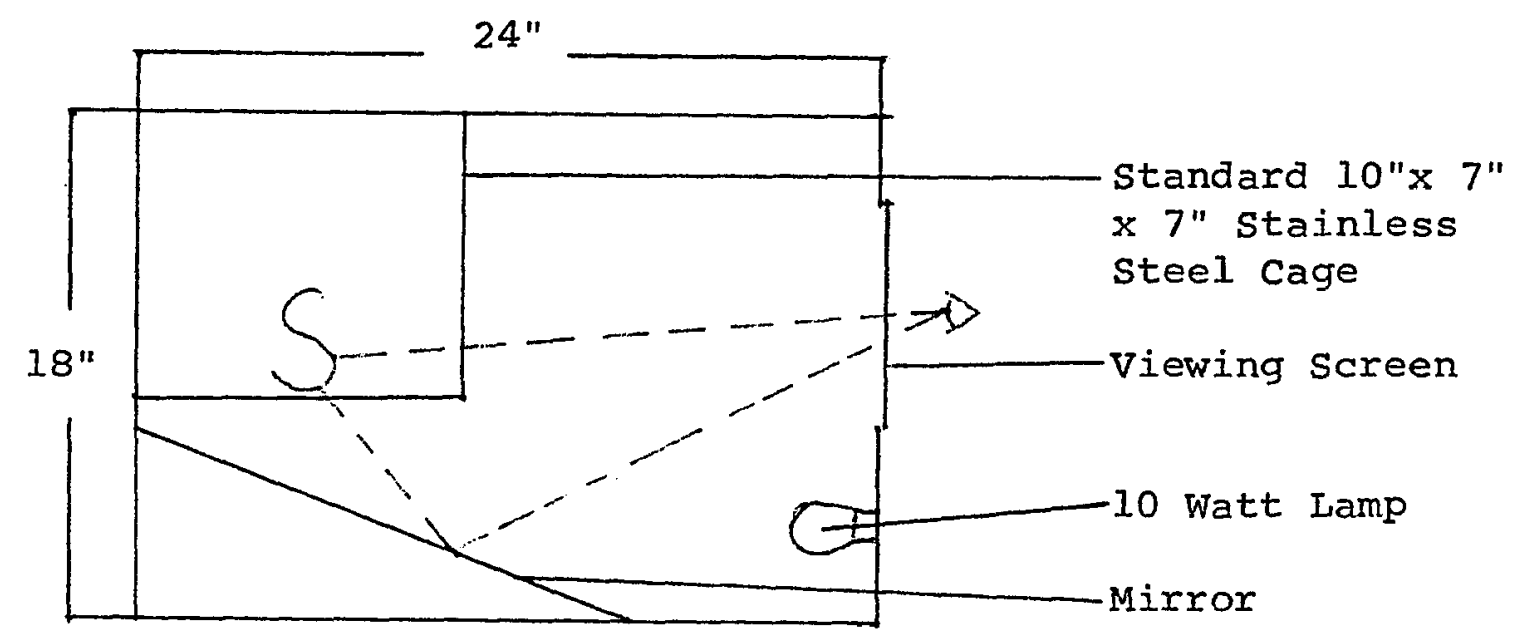




\section{APPENDIX E \\ Reasons for Subject Rejection}

Subject

El-1

E1-2

E1-5

E1-6

E1-7

E.1-8

E1-9

E1-12

E1-13

El-14

E2-1

$E 2-2$

E2-8

E2-9

E2-12

E3-1

E3-3

23-4

aㅛ 1

E4-2

$54-3$

E4-4

84-8

E4-10

C1-7

c1-8
Reason for Rejection

Failed to conceive in four matings (she had) Escaped from collar on 2nd day of exp. Found dead on $3 x d$ day, no apparent reason Failed to conceive in four matings (she had) Found dead on 3rd day, no apparent reason severely injured by male on night of mating Failed to conceive in four matings (she had) Decollared because of severe neck soreness Failed to conceive in four matings Judged to have conceived but-not impregnated

Escaped from collar on 21st day of exp. Escaped from collar on 26th day of exp. Decollared because of severe neck soreness Developed severe eye infection Judged to have conceived-but not impregnated

Decollared because of severe neck soreness Judged to have conceived-but not impregnated Decollared because of severe neck soreness

railed to conceive in four matings (she had) Failed to conceive in four matings (she had) Severely injured by male on night of mating Found dead on $3 r d$ day, no apparent reason Began iltter delivery before being decollared Judged to have conceived-but not impregnated

Judged to have conceived-but not impregnated Escaped from cage one night and was impregnated by a male which also happened to have gotten out that sight 


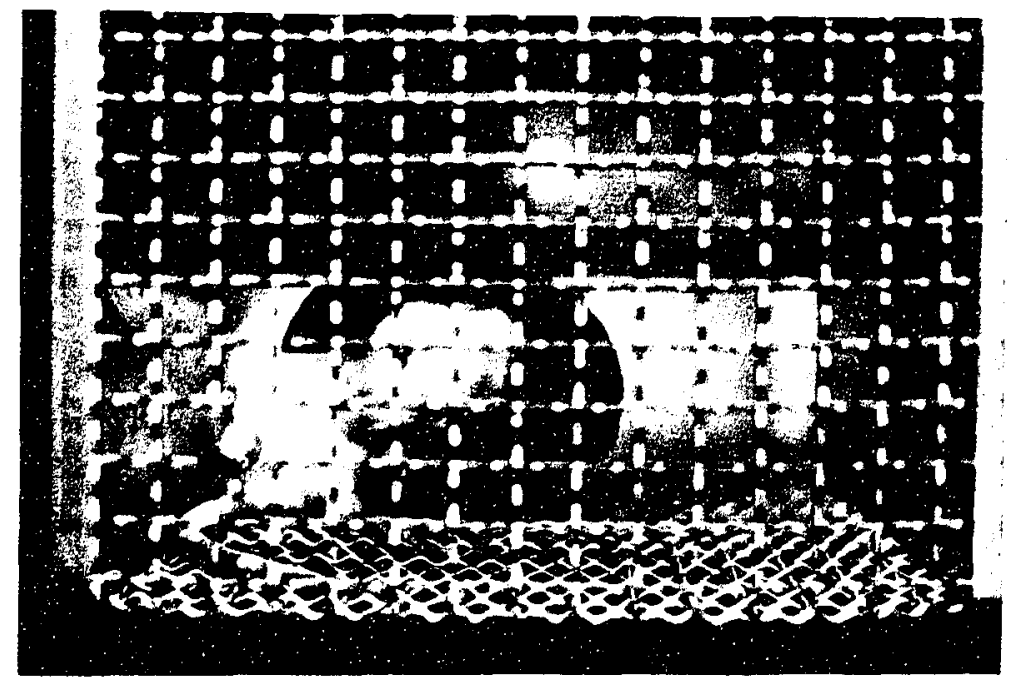

Figure 2. Body-1icking by a notched collax subject.

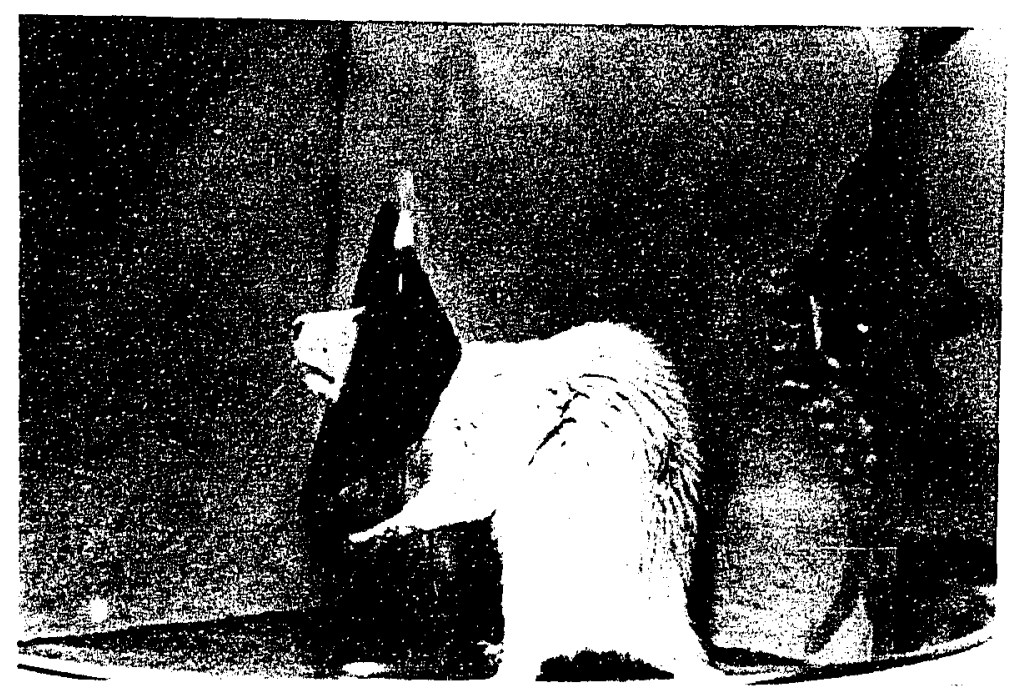

Figure 3. Crouch position adopted by an unnotched collar subject during "Phantom" face-washing. 


\section{APPEADDIX G}

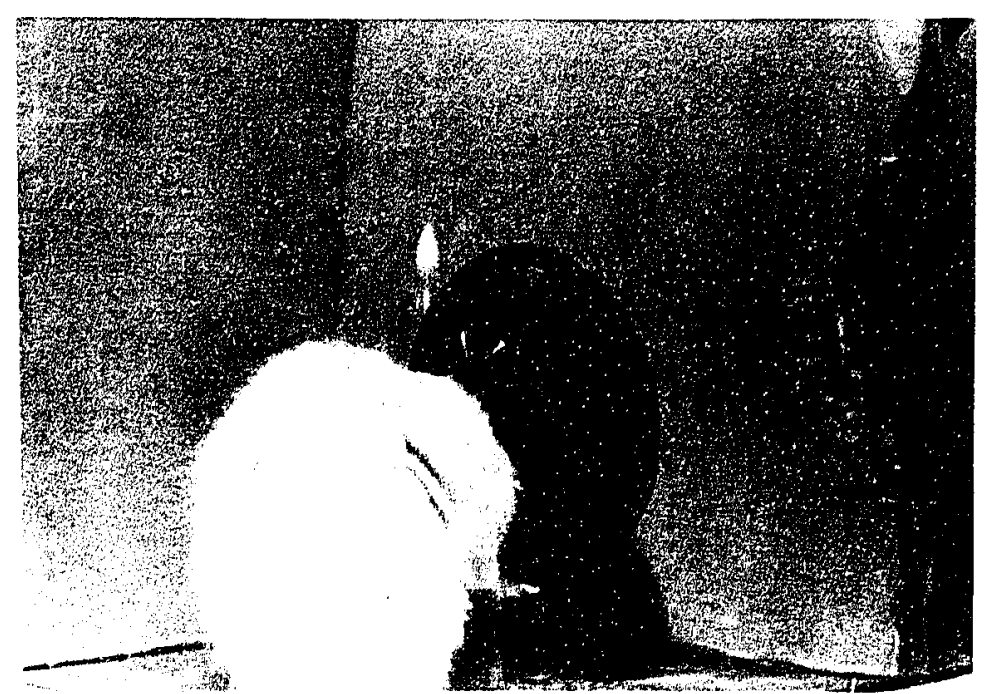

Figure 4. "Phantom" forepaw-licking by an unnotched collar subject.

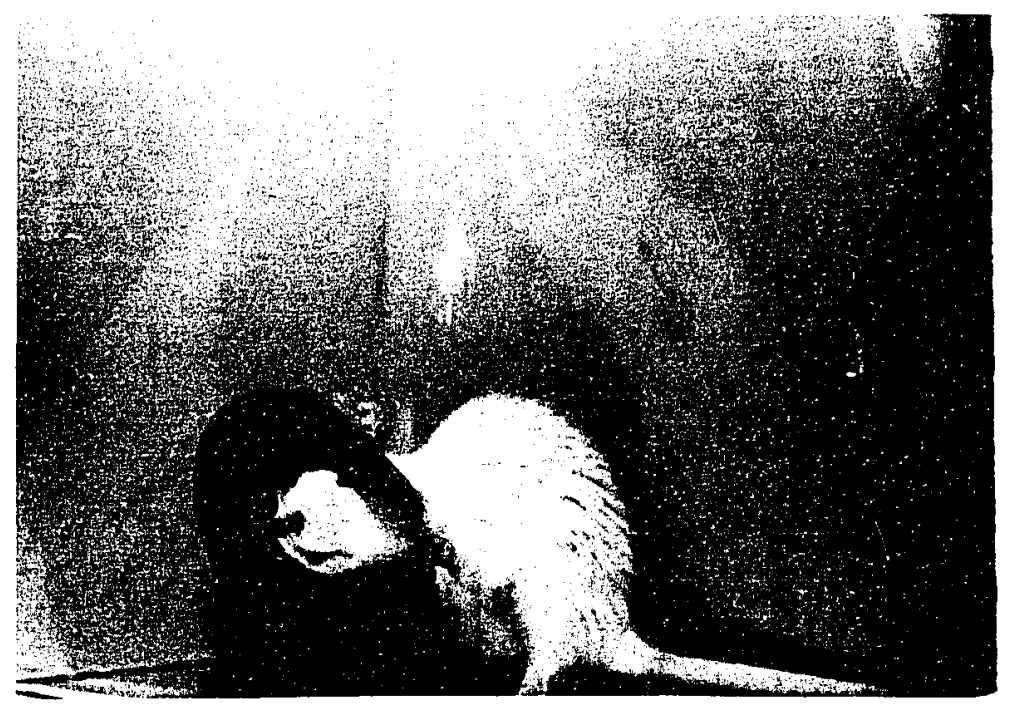

Figure 5. "Phantom" collar-brushing by an unnotched collar subject. 


\section{APPEADIX $\mathrm{H}$}

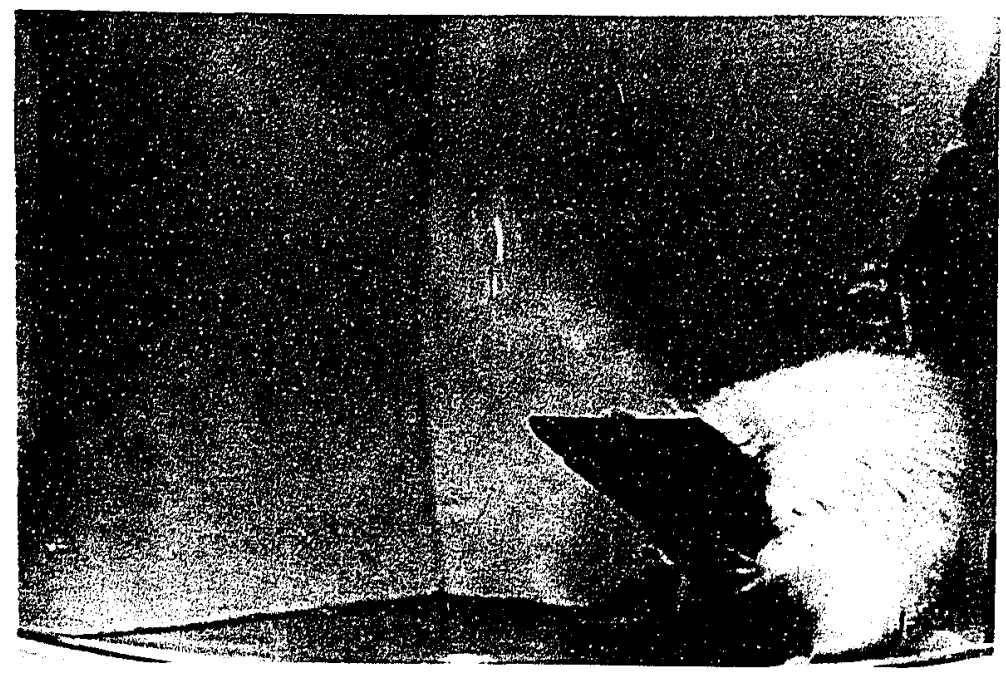

Figure 6. "Phantom" body grooming by an unnotched collar subject.

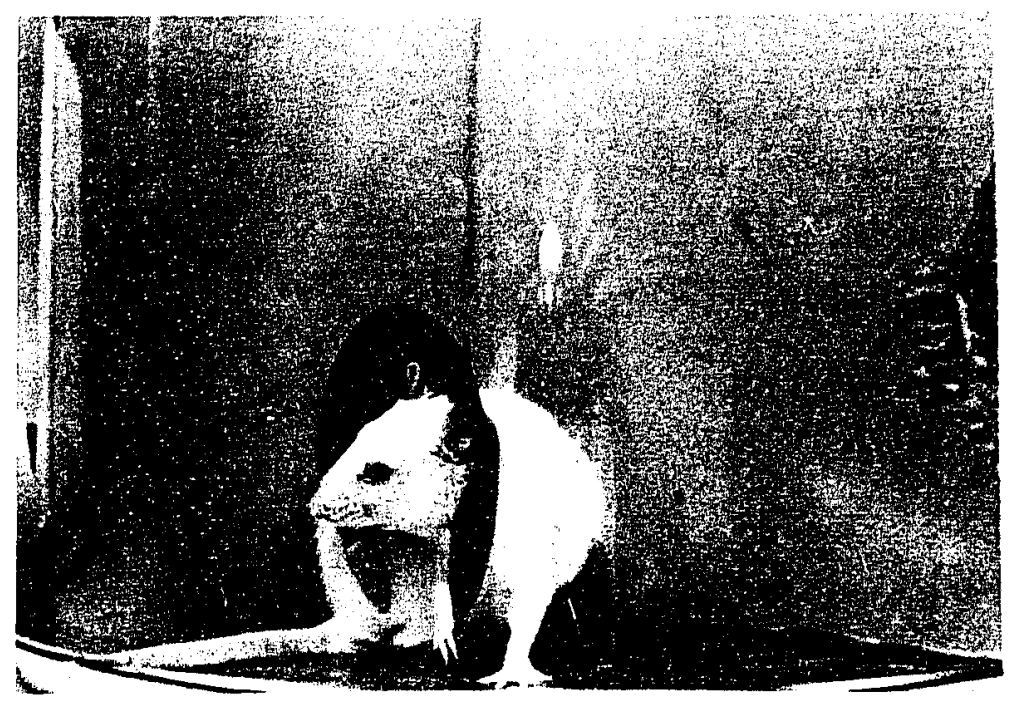

Figure 7. Notched collar subject Jicking hind claw. 


\section{APPEHDIX I}

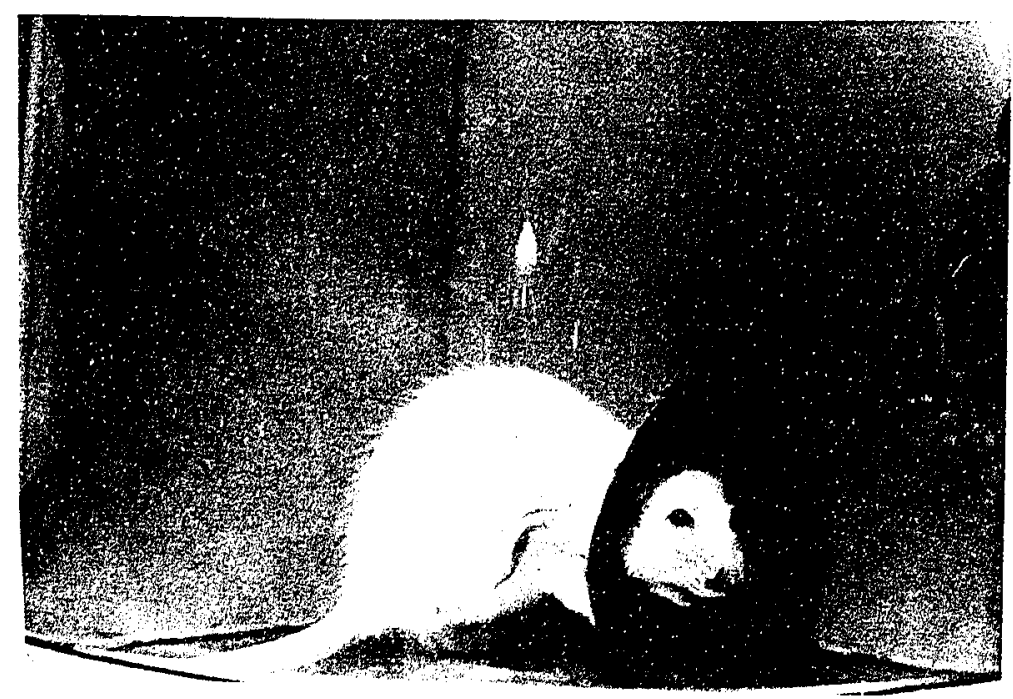

Figure 8. "Phantom" hind-claw-licking by an unnotched collar subject. 


\section{APPENDIX J}

Parental population Weights at Twenty-One Days of Age (gm.)

$\begin{array}{cccccc}\text { Subject No. } & E 1 & \text { E2 } & E 3 & E 4 & C 1 \\ 1 & 37 & 33 & 27 & 30 & 32 \\ 2 & 23 & 32 & 28 & 30 & 27 \\ 3 & 34 & 31 & 24 & 37 & 27 \\ 4 & 29 & 32 & 33 & 25 & 31 \\ 5 & 46 & 32 & 28 & 26 & 32 \\ 6 & 37 & 48 & 34 & 30 & 24 \\ 7 & 33 & 26 & 50 & 38 & 35 \\ 8 & 29 & 27 & 32 & 27 & 29 \\ \text { Total } & 268 & 261 & 256 & 243 & 237 \\ \text { Group Mean } & 33.5 & 32.6 & 32.0 & 30.4 & 29.6\end{array}$


APPENDIX K

Parental Population Weights on Firgt Day of Pregnancy (gm.)

Subject No.

E1

E2

E3

$\mathbf{P} 4$

c1.

1

207

184

218

222

220

213

204

259

3208

240

235

240

213

220

229

246

4

188

166

259

242

291

5

1038

1030

228

242

231

Total

1038

1105

1152

1267

Group Mean

207.6206 .0

221.0

$230.4 \quad 253.4$ 


\section{APPINDIX I}

Parental population Weights on the Twenty-First Day of Pregnancy (gm.)

subject No.

1
2
3
4
5

1
2
3
4
5

Total

Group Mean
E1

314

322

316

313

294

1559

311.8
E2

296

308

340

314

346

1604

320.8
E4

325

350

332

353

330

326

1700

1611

1700

1753

$322.2 \quad 340.0 \quad 350.6$




\section{APPENDTX M}

\section{Abdominal-Genital Cleanliness Scores}

subject No.

EI

E2

E3

E4

C1

1
2
3
4
5
6
7
8

3.0

2.0

2.0

1.0

2.0

1.0

22.5

3.0

2.5

1.0

1.0

1.0

4

2.0

3.5

1.0

1.5

1.0

4.0

2.5

1.5

1.5

1.0

3.0

3.5

1.0

1.0

1.5

2.5

1.5

1.0

1.0

1.0

7

3.5

2.0

1.0

1.0

1.0

1.0

1.0

1.0

Total

23.5

19.5

8.5

10.0

8.5

Group Maan

2.9

2.4

1.1

1.3

1.1 
APPENDIX N

Eighty-Fifth Day Licking Behaviour Mean Scores (sec.)

Subject No.

E1

$\mathrm{E2}$

E3

E4

cl

$\begin{array}{rrrrrr}1 & 4.25 & 17.25 & 12.50 & 30.50 & 8.50 \\ 2 & 8.00 & 12.25 & 17.50 & 42.00 & 24.50 \\ 3 & 27.50 & 12.50 & 17.75 & 23.00 & 22.75 \\ 4 & 18.25 & 5.50 & 33.00 & 19.50 & 10.75 \\ 5 & 29.75 & 11.00 & 18.50 & 18.00 & 20.75 \\ 6 & 3.25 & 6.25 & 7.75 & 30.00 & 2.00 \\ 7 & 6.50 & 8.25 & 18.50 & 11.75 & 2.25 \\ 8 & 14.00 & 14.00 & 14.00 & 5.75 & 14.25\end{array}$

Body-1icking 28.00

8.00

139.50

177.50

105.75

Collar-1icking 0.00

0.00

0.00

0.00

0.00

"Phantom"

83.50

79.50

0.00

3.00

0.00

Total

111.50

87.50

139.50

180.50

105.75

Group Mean

$$
13.94 \quad 10.94
$$

17.44

20.08

13.22 
APPENDIX 0

Contact Latencies on Firgt-Day Retrieving Teat (sec.)

Subject No.

E1

E2

E3

E4

c1

1

2

3

4

3.5

7.5

22.5

37.0

7.0

19.0

44.0

19.5

24.0

26.0

19.0

8.5

5.0

20.0

40.5

10.0

15.0

5

56.0

9.5

54.0

32.5

58.0

8. 5

4.5

Total

111.0

205.5

151.5

103.5

102.0

Group Mean

22.2

21.1

30.3

20.7

20.4 
APPWEDIX p

Contact Latencies on Fifth-Day Retrieving Test (sec.)

Subject No.

EI

E2

E3

E4

CI

1

12.0

5.0

15.5

32.5

4.5

2

8.0

16.0

27.0

5.0

6.0

3

7.5

5.0

15.0

74.0

9.0

12.5

4.5

14.0

42.0

12.0

motal

40.0

30.5

71.5

153.5

31.5

Group Mean

10.0

7.8

17.9

38.5

7.9 


\section{APPENDIX $Q$}

Percentage of Pups Retrieved on First-Day Retrieving Test

$\begin{array}{crrrrr}\text { Subject NO. } & \text { E1 } & \text { E2 } & \text { E3 } & \text { E4 } & \text { CI } \\ 1 & 100 & 100 & 100 & 100 & 100 \\ 2 & 100 & 100 & 100 & 100 & 100 \\ 3 & 0 & 100 & 100 & 100 & 100 \\ 4 & 100 & 100 & 100 & 100 & 100 \\ 5 & 0 & 100 & 100 & 100 & 100 \\ \text { Tota1 } & 300 & 500 & 500 & 500 & 500 \\ \text { Group Mean } & 60 & 100 & 100 & 100 & 100\end{array}$


MPQENDIX

Pexcentage of Pups Retxierod on Fiftr-Day Retrieving Test

Subject No.

E1

2

53

20

c

3
2
3
4

100.0

300.0

300.0

300.0

100.0

0.0

2

75.0

100.0

100.0

0.0

36.4

$100+0$

100.5

0.0

0.0

$83 \cdot 3$

100.0

roten 1

275.0

200.0

336.4

$283 \cdot 3$

100.0

comp Nean

$$
68 .
$$

50

94. 1

70.8

300.0

75.0 


\section{APPENDIX $\mathbf{S}$}

\section{Pup Survival Percentage}

Subject No.

E1.

E2

E3

E4

cl

$\begin{array}{rrrrrr}1 & 50.0 & 100.0 & 80.0 & 100.0 & 92.3 \\ 2 & 100.0 & 100.0 & 100.0 & 100.0 & 0.0 \\ 3 & 100.0 & 90.0 & 83.3 & 100.0 & 100.0 \\ 4 & 44.4 & 0.0 & 77.8 & 0.0 & 53.8 \\ 5 & 92.3 & 100.0 & 100.0 & 100.0 & 100.0 \\ 1 & 386.7 & 390.0 & 441.1 & 400.0 & 346.1 \\ & & & & & \\ & 77.3 & 78.0 & 88.2 & 80.0 & 69.2\end{array}$

Group Mean

77.3

78.0

88.2

80.0

69.2 


\section{BIBLIOGRAPHY}

Beach, F.A. The descent of instinct, Psychol. Rev. 1955, 62, $401-410$.

Bindra, D. Motivation: A Systematic Reinterpretation. New York: Ronald Press, 1959.

Birch, H.G. Sources of order in the maternal behaviour of animals, Amer. J. of Orthopsychiat. 1956, 26, 279-284.

Boring, E.G. A History of Experimental Psychology. New York: Appleton-Century-Crofts, 1950.

Christophersen, E.R. \& Wagman, W. Maternal behaviour in the albino rat as a function of self-licking deprivation, J. of Comp. and Physio. Psychol. 1965, 60, 142-144.

Dennis, W. Readings in the History of Psychology. New York: Appleton-Century-Crofts, 1948.

Edwards, A.I. Experimental Design in Psychological Research. New York: Holt, Rinehart, and Winston, 1960.

Eibl-Eibesfeldt, I. The interactions of unlearned behaviour patterns and learning in mammals, Brain Mechanisms and Learning: A Symposium. Oxford: Alden Press, 1961.

Ferguson, G.A. Statistical Analysis in Psychology and Education. New York: McGraw-Hill, 1959.

Freund, J.E. Modern Elementary Statistics. New Jersey: Prentice-Hall, 1960.

Gilman, J.P.W. Professor of Anatomy, University of Guelph, Personal Communication.

Grollman, A. Essentials of Endocrinology. Philadelphia: J.D. Lippincott Co., 1947.

Lane-Petter, W. Animals for Research. Iondon: Academic Press, 1964. 
Lorenz, $\mathrm{K}$. The comparative method in studying innate behaviour patterns, Symposia, Soc. Exper. Biol. 1950, 4, Cambridge University Press.

Maier, N.R.F. \& Schneirla, T.C. Principles of Animal Psychology. New York: Dover Publications, 1964.

Moltz, H. \& Robbins, D. Maternal behaviour of primiparous and multiparous rats, J. of Comp. and Physio. Psychol. $1965,60,417-421$.

Munn, N.L. Handbook of Psychological Research on the Rat. New York: Houghton Mifflin Co., 1950.

Postman, L. Psychology in the Making. New York: Knopf Publications, 1962.

Ratner, S.C. \& Denny, M.R. Comparative Psychology. Homewood, Illinois: Dorsey Press, 1964.

Reiss, B.F. The effect of altered environment and of age on mother-young relationships among animals, Ann. N.Y. Acad. Sci. 1954, 57, 606-610.

Rheingold, H.L. Maternal Behaviour in Mammals. New York: John Wiley \& Sons, 1963.

Stone, C.D. Comparative Psychology. New Jersey: PrenticeHall, 1951.

Tinbergen, N. The Study of Instinct. Oxford: oxford University Press, 1951 .

Turner, C.D. General Endocrinology. Philadelphia: W.D. Saunders Co., 1949.

Waters, R.H., Rethlingshafer, D.A. \& Caldwell, W.E. Principles of Comparative Psychology. New York: McGrawHill, 1960 .

Zarrow, M.X. Experimental Endocrinology. London: Academic Press, 1963. 
VITA AUCTORIS

1943 Born in Brantford, Ontario, to Louis Horvath and Teresa Gorcsi.

1949-61 Educated at Pleasant Ridge Public School, Hartford Public School, Waterford District High School, and Brantford C.I. \& V.S.

1965

Graduated with the degree of B.A., Waterloo University College, Waterloo, Ontario. Registered as full-time graduate student at University of windsor. 